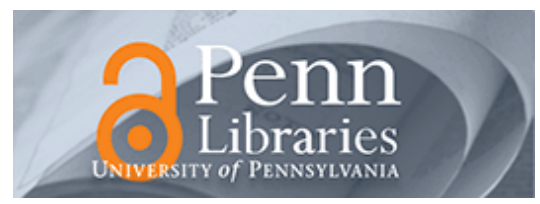

University of Pennsylvania

ScholarlyCommons

\title{
Corporate Leniency Programs When Firms Have Private Information: The Push of Prosecution and the Pull of Pre-emption
}

Joseph E. Harrington Jr

University of Pennsylvania

Follow this and additional works at: https://repository.upenn.edu/bepp_papers

Part of the Industrial Organization Commons

\section{Recommended Citation}

Harrington, J. E. (2013). Corporate Leniency Programs When Firms Have Private Information: The Push of Prosecution and the Pull of Pre-emption. The Journal of Industrial Economics, 61 (1), 1-27.

http://dx.doi.org/10.1111/joie.12014

This paper is posted at ScholarlyCommons. https://repository.upenn.edu/bepp_papers/91

For more information, please contact repository@pobox.upenn.edu. 


\title{
Corporate Leniency Programs When Firms Have Private Information: The Push of Prosecution and the Pull of Pre-emption
}

\author{
Abstract \\ A corporate leniency program provides relief from government penalties to the first member of a cartel to \\ cooperate with the authorities. This study explores the incentives to apply for leniency when each cartel \\ member has private information as to the likelihood that the competition authority will be able to convict \\ them without a cooperating firm. A firm may apply for leniency because it fears being convicted \\ ('prosecution effect') or because it fears another firm will apply ('pre-emption effect'). Policies by the \\ competition authority to magnify concerns about pre-emption-and thereby induce greater use of the \\ leniency program-are also explored. \\ Disciplines \\ Economics | Industrial Organization
}




\title{
Corporate Leniency with Private Information: The Push of Prosecution and the Pull of Pre-emption*
}

\author{
Joseph E. Harrington, Jr. \\ Department of Economics \\ Johns Hopkins University \\ Baltimore, MD 21218 \\ 410-516-7615, -7600 (Fax) \\ joe.harrington@jhu.edu \\ www.econ.jhu.edu/People/Harrington \\ 10 January 2011 (Preliminary Version - Comments Welcome)
}

\begin{abstract}
A corporate leniency program provides relief from government penalties to the first member of a cartel to come forward and cooperate with the authorities. This study explores the incentives to apply for leniency when each cartel member has private information as to the likelihood that the competition authority will be able to convict them without a cooperating firm. A firm may apply for leniency because it fears being convicted or because it fears another firm will apply. Policies by the competition authority to magnify concerns about pre-emption and thereby induce greater use of the leniency program - are explored.
\end{abstract}

\section{Introduction}

One of the most important policy developments in U.S. antitrust policy in recent decades is the 1993 revision of the Corporate Leniency Program by the Department of Justice (DOJ). Originally created in 1978, this program allows corporations, who are engaging in illegal antitrust activity (such as price-fixing), to receive amnesty from government penalties if they come forward and cooperate. The 1993 revision made it possible for amnesty to be awarded even when an investigation had been started and made it a condition that the DOJ "has not received information about the illegal activity being reported from any other source." This means that amnesty is limited to one firm per cartel. The appeal of these programs for discovering cartels and acquiring the evidence to effectively prosecute them has resulted in the adoption of some form of a corporate leniency program by more than 50 countries and jurisdictions.

\footnotetext{
*I very much appreciate the comments of Faruk Gul and seminar participants at the U. of Copenhagen, and the research assistance of Wei Zhao.
} 
In light of the importance of leniency programs in practice, there has been a considerable amount of research exploring how leniency programs affect the incentives to collude and to report cartels. Beginning with the pioneering paper of Motta and Polo (2003), the primary force in theoretical analyses is that the competition authority may catch the colluding firms and, in anticipation of that prospect, firms may apply for leniency; this I will refer to as the prosecution effect. For example, in Harrington (2008), the probability of the competition authority discovering and successfully prosecuting the cartel varies over time and, when it is sufficiently high, collusion collapses and all firms race for leniency. While the threat of the competition authority catching the cartel is indeed critical, there is another first-order effect which is absent in previous analyses. Referring to it as the pre-emption effect, this is when a firm - which doesn't necessarily believe the competition authority is likely to catch the cartel - is still concerned that another cartel member may apply for leniency and, because of that concern, applies itself. The threat is not being caught by the competition authority but instead a rival firm turning witness. Indeed, in practice, it is typical that one firm pre-empts its rivals by applying for leniency, as opposed to multiple firms racing for leniency. This outcome - whereby a single firm turns in its fellow colluders - runs contrary to the prediction of all previous models which is that either all or no firms apply.

The significance of the pre-emption effect is documented in recent experiments which measure the impact of a leniency program on collusion (Bigoni et al, 2010). Two subjects interact in a price game with the possibility of communication. Prior to selecting price, they each decide whether to press a button that signals a desire to communicate. If both press the button then they are permitted to communicate about price though this also makes them liable for penalties. After their communication, firms simultaneously choose price and decide whether to apply for leniency. If they did communicate and neither firm applied for leniency then there is a fixed probability $p$ that each is assessed a penalty $F$. Various values of $(p, F)$ are considered. Let us define "collusion" as when both firms press the communicate button. The experimental findings show that, for the same expected penalty from the competition authority (that is, holding $p F$ fixed), the frequency of collusion is lower when $F$ is higher (and thus $p$ is lower so that $p F$ is unchanged). This effect is consistent with concerns that a rival will apply for leniency, independent of the threat posed by the competition authority.

The objective of this paper is to develop and explore a model that encompasses the pre-emption effect in order to both better understand the incentives of firms in an environment with a leniency program and to investigate how the competition authority can manipulate those incentives through ancillary instruments in order to make a leniency program more effective. Obviously, the key modelling modification is to allow cartel members to have private information regarding the likelihood that the competition authority may be able to effectively prosecute them. As the introduction of private information is a substantive complication, I explore its role in the postcartel environment; that is, the cartel has collapsed for internal reasons and the objective of each firm is to minimize its expected penalties. Future work will consider 
embedding this setting into an infinitely repeated game so that the impact of the leniency program on the stability of collusion can be explored.

As current intuition regarding the incentive effects of leniency programs is predicated upon firms having common information about the likelihood that they'll be prosecuted, I begin by comparing equilibria with private information to equilibria when there is public information. That analysis identifies and investigates the prosecution and pre-emption effects. I then explore the competition authority expending more resources to make discovery and prosecution (without a leniency applicant) more likely. While such expenditure is clearly advantageous with regards to encouraging leniency, I find that the marginal effect is stronger when firms have private information than when they do not. The source of this effect is a feedback relationship between the prosecution and pre-emption effects.

After describing the model in Section 2, the theoretical literature on leniency programs is reviewed in Section 3 as it pertains to the issue of information. Equilibria are characterized in Section 4 with a comparison of the cases of public and private information in Section 5. I then analyze in Section 6 the effects of a more proactive competition authority when it comes to discovering and prosecuting cartels without use of the leniency program.

\section{General Model}

Consider a cartel composed of two firms for which collusion has ended and firms are independently deciding whether or not to apply for leniency. If a firm is convicted without having received leniency, it pays a fine $F>0$, while if it receives leniency then its fine is $\theta F$ where $\theta \in[0,1)$, so more leniency is associated with a lower value of $\theta$. A firm's only decision is whether or not to apply for leniency and its objective is to minimize expected penalties.

Regarding the decision to apply for leniency, a primary source of uncertainty for a firm is the likelihood that it'll be prosecuted and convicted by the competition authority (CA) when no firm has cooperated through the leniency program; that is, enforcement without assistance of the leniency program. Let $\rho$ denote the probability of a conviction when no firm has applied for leniency. $\rho$ is a random variable from the perspective of firms and, prior to making a leniency decision, firm $i$ receives a private signal $s_{i} \in[\underline{s}, \bar{s}]$ of $\rho$. After learning their signals, firms simultaneously decide whether or not to apply for leniency. A strategy for a firm is then of the form: $\phi:[\underline{s}, \bar{s}] \rightarrow\{$ Apply, Do not apply $\}$.

As a firm's signal is presumably informative as to the true $\rho$, firms' signals will be positively correlated. Though firm $i$ does not get to observe firm $j$ 's signal, it will have some information as to $s_{j}$ by virtue of $s_{i}$. Let $H\left(s_{j} \mid s_{i}\right)$ be firm $i$ 's cdf on firm $j$ 's signal conditional on its own signal, $i, j=1,2$ and $i \neq j$. To capture the positive correlation between firms' signals, assume A1.

A1 $H\left(s_{j} \mid s_{i}\right)(j \neq i)$ is continuously differentiable in $s_{i}$ and $s_{j}$. If $s^{\prime \prime}>s^{\prime}$ then $H\left(\cdot \mid s_{i}=s^{\prime \prime}\right)$ first-order stochastically dominates (FOSD) $H\left(\cdot \mid s_{i}=s^{\prime}\right)$. 
A higher signal for a firm results in it attaching more probability to high signals for its rival.

If only one firm applied for leniency then it pays a penalty of $\theta F$ and the other firm pays $F$ (hence, it is assumed conviction occurs for sure because of a cooperating cartel member). If both firms apply for leniency then each has an equal chance of being the one to receive leniency, so each has an expected fine of $\left(\frac{1+\theta}{2}\right) F$. If no one applied for leniency then firms are convicted with probability $\rho$ and each pays $F$ in that event, which means firm $i$ 's expectation on its penalty is $E\left[\rho \mid s_{i}\right] F$ where $E\left[\rho \mid s_{i}\right]$ is its expectation on $\rho$ conditional on its signal. It is assumed that:

A2 $E\left[\rho \mid s_{i}\right]:[\underline{s}, \bar{s}] \rightarrow(0,1)$ is continuously differentiable and increasing in $s_{i}$.

In light of preceding research focusing on the case of public signals, I will begin Section 4 by comparing the incentives between when signals are private and they are public in order to identify the unique features introduced by allowing firms to have private information. To do so, a game when firms' signals $\left(s_{1}, s_{2}\right)$ are common knowledge is explored so that, when they simultaneously decide whether or not to apply for leniency, they have a common expectation $E\left[\rho \mid s_{1}, s_{2}\right]$ on $\rho$. A firm's strategy is then of the form $\psi:[\underline{s}, \bar{s}]^{2} \rightarrow\{$ Apply, Do not apply\}. Assume A3.

A3 $E\left[\rho \mid s_{1}, s_{2}\right]:[\underline{s}, \bar{s}] \rightarrow(0,1)$ is continuously differentiable, responds symmetrically to $s_{1}$ and $s_{2}$, and is increasing in $s_{1}$ and $s_{2}$.

As needed, additional structure will be added later.

\section{Literature Review}

Since the main modelling innovation of this paper is in terms of information, the literature review will focus on the informational assumptions of previous work and their implications. For a more complete review of research on leniency programs, see Spagnolo (2008).

The initial class of models examining the effect of a leniency program on cartel stability modified the standard infinitely repeated oligopoly game (usually, the Prisoners' Dilemma) by assuming that, in each period that firms are colluding, there is a fixed probability $\rho$ that firms are caught by the CA - in which case they pay a fixed penalty - and firms have the option to apply for leniency to receive reduced penalties. Firms make the leniency decision simultaneously and models differ in terms of whether it occurs after the current period's prices are revealed (e.g., Motta and Polo, 2003) or a firm makes its price and leniency decisions simultaneously, in which case it can undercut the collusive price and apply for leniency at the same time (e.g., Harrington and Chang, 2010). ${ }^{1}$ With $\rho$ being fixed and known over time, the stationarity of the environment implies that if equilibrium involves firms colluding then

\footnotetext{
${ }^{1}$ Bigoni et al (2010) conduct experiments and allow subjects both to apply for leniency when setting its price or, in the event that no firm has applied for leniency, to apply after prices are revealed and firms learn whether or not there was a deviation.
} 
firms never apply for leniency. For if leniency is used as part of an equilibrium then, given stationarity, it occurs in the first period but if conviction prevents reformation of the cartel (for a sufficiently long time) then firms would cheat in the initial period (as they anticipate collusion ending because a firm applied for leniency) which then makes collusion unstable. For reasonable parameter values, a fixed and known value for $\rho$ implies that leniency is not used in equilibrium. ${ }^{2}$

In practice, firms do form a cartel and then may, at some point in time, apply for leniency. This will occur if the environment changes so that it was initially optimal for firms to collude and not apply for leniency, but at some later time it becomes optimal to apply. This possibility is explored in Harrington (2008) where it is assumed $\rho$ is not fixed - it is iid over time - but the assumption that $\rho$ is public information among firms is maintained. A Pareto-efficient equilibrium is now characterized by a cut-off value for $\rho$ such that if $\rho$ exceeds that cut-off then firms stop colluding and all apply for leniency - because the prospects of being caught by the CA are sufficiently great so as to cause the cartel to collapse - and otherwise firms collude and do not apply. ${ }^{3}$

While allowing $\rho$ to change over time is able to generate an equilibrium outcome in which firms collude for some length of time and then use the leniency program consistent with observed cartel behavior - it has the unappealing property that either all firms apply or none do. This is due to firms' information being common, for if one firm applies for leniency then the optimal action for a rival firm is to apply as well. To generate what we actually do observe - a single firm applying for leniency it is essential to allow for private information.

It is worth noting that there have been some analyses to allow for private information in a limited way. Silbye (2010b) assumes $\rho$ is common knowledge but each firm possesses evidence that it could submit to convict the other firm if it applied for leniency. $\varepsilon_{i} \in[0,1-\rho]$ is the evidence possessed by firm $i$ to assist in convicting firm $j$ and is private information to firm $i$. If firm $i$ receives leniency then firm $j$ 's expected penalty is $\left(\rho+\varepsilon_{i}\right) F$. If no one applies then each has an expected fine of $\rho F$, which, as noted, is common knowledge. Sauvagnat (2010) allows the CA to have private information about the strength of its case and it is a strategic decision whether to open an investigation. (Previous work implicitly allowed for such private information but assumed the start of an investigation was exogenous.) Of particular relevance is that the CA may open an investigation even when its case is weak, as doing so may induce firms to apply for leniency. Finally, Pinna (2010) considers a strategic setting in which firms know whether or not they are colluding but the CA does not.

\footnotetext{
${ }^{2}$ There is also an equilibrium - referred to as "collude and report" - in Motta and Polo (2003) for which firms collude and apply for leniency in every period. This occurs when the cartel can immediately reform and leniency is sufficiently generous. Though it can be an equilibrium, I do not believe it is an empirically relevant solution.

${ }^{3}$ Harrington (2008) also considers a policy space which provides leniency if and only if $\rho$ is sufficiently low (i.e., the competition authority's case is not too strong). Silbye (2010a) enriches the policy space to when the amount of leniency can depend continuously on $\rho$.
} 


\section{Characterization of Equilibrium}

\subsection{Public Signals}

To appreciate the new forces introduced with private information, let us begin by characterizing equilibrium when firms' signals $\left(s_{1}, s_{2}\right)$ are public information. First note that there are only symmetric equilibria since applying for leniency is optimal when the other firm applies. Hence, either both apply or neither apply. The set of Bayes-Nash equilibria is:

$$
\psi\left(s_{1}, s_{2}\right)= \begin{cases}\text { Apply } & \text { if }\left(s_{1}, s_{2}\right) \notin \Omega \\ \text { Do not apply } & \text { if }\left(s_{1}, s_{2}\right) \in \Omega\end{cases}
$$

where

$$
E\left[\rho \mid s_{1}, s_{2}\right] \leq \theta \forall\left(s_{1}, s_{2}\right) \in \Omega .
$$

If $\left(s_{1}, s_{2}\right) \notin \Omega$, so that a firm's rival is going to apply for leniency, it is optimal for a firm to apply as well, as an expected penalty of $\left(\frac{1+\theta}{2}\right) F$ is preferred to a sure penalty of $F$. Now consider $\left(s_{1}, s_{2}\right) \in \Omega$ so that a firm's rival is not expected to apply for leniency. If a firm does not apply then its expected penalty is $E\left[\rho \mid s_{1}, s_{2}\right] F$, while it is $\theta F$ from applying. Hence, not applying is optimal if and only if (iff) $E\left[\rho \mid s_{1}, s_{2}\right] \leq \theta$. As long as

$$
\theta>E\left[\rho \mid s_{1}=\underline{s}, s_{2}=\underline{s}\right],
$$

so there are some signals for which it is equilibrium behavior for both not to apply, there are an infinite number of equilibria as there are an infinite number of sets $\Omega$ satisfying (2).

Notice that if $\left(s_{1}, s_{2}\right) \notin \Omega$ and $E\left[\rho \mid s_{1}, s_{2}\right]<\theta$ then firms are incurring higher penalties by both applying for leniency than if both did not, as

$$
E\left[\rho \mid s_{1}, s_{2}\right] F<\theta F<\left(\frac{1+\theta}{2}\right) F,
$$

where the term to the left of the first inequality is the expected penalty from both not applying and the term to the right of the second inequality is from both applying. This makes it useful to define the Pareto-efficient equilibrium,

$$
\Omega^{*} \equiv\left\{\left(s_{1}, s_{2}\right): E\left[\rho \mid s_{1}, s_{2}\right] \leq \theta\right\},
$$

which has firms not apply whenever it is an equilibrium. This equilibrium minimizes expected penalties. Note that if

$$
\theta<E\left[\rho \mid s_{1}, s_{2}\right]<\frac{1+\theta}{2},
$$

expected penalties are higher with both applying compared to both not applying but it is not an equilibrium for both not to apply given those signals. In Harrington (2008), this is referred to as the Race to the Courthouse effect, and it serves to deter cartel formation by increasing expected penalties. 


\subsection{Private Signals}

Now suppose firms' signals are private information, and consider a symmetric strategy profile which is a cut-off strategy:

$$
\phi\left(s_{i}\right)= \begin{cases}\text { Do not apply } & \text { if } s_{i} \in[\underline{s}, x] \\ \text { Apply } & \text { if } s_{i} \in(x, \bar{s}]\end{cases}
$$

A firm applies for leniency iff its signal exceeds $x$. The set of symmetric cut-off BayesNash equilibrium can then be characterized by the set of values for $x$ such that $\phi$ is a Bayes-Nash equilibrium. Given firm 2 uses this strategy, the expected penalty to firm 1 from not applying is

$$
\int_{\underline{s}}^{x} E\left[\rho \mid s_{1}, s_{2}\right] F H^{\prime}\left(s_{2} \mid s_{1}\right) d s_{2}+\left[1-H\left(x \mid s_{1}\right)\right] F
$$

or

$$
H\left(x \mid s_{1}\right) E\left[\rho \mid s_{1}, s_{2} \leq x\right] F+\left[1-H\left(x \mid s_{1}\right)\right] F .
$$

If $s_{2} \leq x$ then firm 2's signal is sufficiently low that it does not apply in which case firm 1's expected penalty from not applying is its expectation on $\rho$ multiplied by $F$. This expectation, $E\left[\rho \mid s_{1}, s_{2} \leq x\right]$, is conditional on firm 1's signal and firm 2 not applying for leniency. If $s_{2}>x$ then firm 2 applies for leniency in which case, by not applying, firm 1 is convicted and pays $F$. If instead firm 1 applies for leniency then its expected penalty is

$$
H\left(x \mid s_{1}\right) \theta F+\left[1-H\left(x \mid s_{1}\right)\right]\left(\frac{1+\theta}{2}\right) F .
$$

If $s_{2} \leq x$ then it is the only firm to apply for leniency so its penalty is $\theta F$, while if $s_{2}>x$ then both firms have applied in which case firm 1's expected penalty is $\left(\frac{1+\theta}{2}\right) F$.

Firm 1 strictly prefers to apply for leniency iff (4) exceeds (5):

$H\left(x \mid s_{1}\right) E\left[\rho \mid s_{1}, s_{2} \leq x\right] F+\left[1-H\left(x \mid s_{1}\right)\right] F>H\left(x \mid s_{1}\right) \theta F+\left[1-H\left(x \mid s_{1}\right)\right]\left(\frac{1+\theta}{2}\right) F$,

where recall that each firm is making a choice to minimize expected penalties. This expression can be re-arranged to

$$
E\left[\rho \mid s_{1}, s_{2} \leq x\right]>\theta-\left(\frac{1-\theta}{2}\right)\left[\frac{1-H\left(x \mid s_{1}\right)}{H\left(x \mid s_{1}\right)}\right] .
$$

It is optimal to apply for leniency when the expected probability of being caught by the CA - given no firm is a cooperating witness through the leniency program is sufficiently large relative to the leniency parameter $\theta$. The relevant expectation on being caught by the $\mathrm{CA}$ is for when no one applies for leniency, which is the 
expectation on $\rho$ conditional on a firm's own signal and its rival's signal is sufficiently low that it does not apply for leniency. ${ }^{4}$

Using (7), define

$$
\Delta\left(s_{1}, x\right) \equiv E\left[\rho \mid s_{1}, s_{2} \leq x\right]-\theta+\left(\frac{1-\theta}{2}\right)\left[\frac{1-H\left(x \mid s_{1}\right)}{H\left(x \mid s_{1}\right)}\right] .
$$

Given signal $s_{1}$ and threshold $x$, applying is optimal for firm 1 iff $\Delta\left(s_{1}, x\right)>0$. Next note that leniency becomes relatively more attractive when a firm's own signal is higher since a higher signal makes it more likely it'll be caught by the CA:

$$
\frac{\partial \Delta\left(s_{1}, x\right)}{\partial s_{1}}=\frac{\partial E\left[\rho \mid s_{1}, s_{2} \leq x\right]}{\partial s_{1}}-\left(\frac{1-\theta}{2}\right)\left[\frac{\partial H\left(x \mid s_{1}\right) / \partial s_{1}}{H\left(x \mid s_{1}\right)^{2}}\right]>0
$$

as

$$
\frac{\partial E\left[\rho \mid s_{1}, s_{2} \leq x\right]}{\partial s_{1}}>0
$$

by $\mathrm{A} 2$ and

$$
\frac{\partial H\left(x \mid s_{1}\right)}{\partial s_{1}} \leq 0
$$

by A1. Hence, applying for leniency is optimal when $s_{1}>x$ iff $\Delta(x, x) \geq 0$, as then $\Delta\left(s_{1}, x\right)>0, \forall s_{1}>x$. Not applying is optimal when $s_{1}<x$ iff $\Delta(x, x) \leq 0$, as then $\Delta\left(s_{1}, x\right)<0, \forall s_{1}<x$. Therefore, if $x \in(\underline{s}, \bar{s})$ then $\phi$ is a Bayes-Nash equilibrium iff $\Delta(x, x)=0$.

Define

$$
\begin{aligned}
\Phi(x) & \equiv \Gamma(x) \Delta(x, x) \\
& =\Gamma(x)\left\{E\left[\rho \mid s_{1}=x, s_{2} \leq x\right]-\theta\right\}+\left(\frac{1-\theta}{2}\right)[1-\Gamma(x)],
\end{aligned}
$$

where $\Gamma(x) \equiv H(x \mid x)$ is the probability that $s_{2} \leq x$ conditional on $s_{1}=x$. In some of the analysis, it'll be easier to work with $\Phi(x)$, rather than $\Delta(x, x)$, because it is bounded as $x \rightarrow \underline{s}$. Here are some sufficient conditions for equilibrium, with the first condition summarizing the preceding analysis.

- If $\Phi\left(s^{\prime}\right)=0$ then $x=s^{\prime}$ is an equilibrium cut-off.

- $x=\underline{s}$ is an equilibrium cut-off. Note that

$$
\begin{aligned}
\Phi(\underline{s}) & =H\left(\underline{s} \mid s_{1}=\underline{s}\right)\left\{E\left[\rho \mid s_{1}=\underline{s}, s_{2} \leq \underline{s}\right]-\theta\right\}+\left(\frac{1-\theta}{2}\right)\left[1-H\left(\underline{s} \mid s_{1}=\underline{s}\right)\right] \\
& =\frac{1-\theta}{2}>0
\end{aligned}
$$

\footnotetext{
${ }^{4}$ The intuition is analogous to that for auctions when bidders have affiliated values. A bidder selects its bid based on beliefs over the true value when its bid matters for its payoff, which is when its signal is the highest as then its bid is the highest so it wins the item. Analogously, a firm evaluates the payoff from not applying for leniency using beliefs as to the likelihood of being caught by the CA when such beliefs matter, which is when the other firm's signal is sufficiently low that it does not apply for leniency.
} 
which, by (8), means $\Delta\left(s_{1}, \underline{s}\right)>0 \forall s_{1}$, and, therefore, applying is strictly preferred to not applying for all signals. In other words, if a rival is going to apply for leniency for sure (that is, for every signal) then it is optimal to do so as well.

- If $\Phi(\bar{s}) \leq 0$ then $x=\bar{s}$ is an equilibrium cut-off. Again by (8), $\Delta\left(s_{1}, \bar{s}\right) \leq 0 \forall$ $s_{1}<\bar{s}$, which implies it is never optimal to apply. Thus, not applying for all signals is an equilibrium if, conditional on the other firm never applying, a firm prefers not to apply even when it receives the strongest signal $\bar{s}$.

- If

$$
E\left[\rho \mid s_{1}=\bar{s}\right]<\theta
$$

then there are at least three equilibria: $x \in\left\{\underline{s}, s^{\prime}, \bar{s}\right\}$ for some $s^{\prime} \in(\underline{s}, \bar{s})$. This follows from:

$$
\Phi(\underline{s})=\frac{1-\theta}{2}>0>E\left[\rho \mid s_{1}=\bar{s}, s_{2} \leq \bar{s}\right]-\theta=\Phi(\bar{s})
$$

and noting that $E\left[\rho \mid s_{1}=\bar{s}, s_{2} \leq \bar{s}\right]=E\left[\rho \mid s_{1}=\bar{s}\right]$. By continuity, $\exists s^{\prime} \in(\underline{s}, \bar{s})$ such that $\Phi\left(s^{\prime}\right)=0$.

Multiplicity of cut-off equilibria is common, for if there is an equilibrium in which the leniency program is not always used, $x \in(\underline{s}, \bar{s}]$, then there are multiple equilibria since $x=\underline{s}$ is always an equilibrium. It will some times be helpful to consider the Pareto-efficient symmetric cut-off Bayes-Nash equilibrium which is the equilibrium with the highest threshold $x$, as I will now show it minimizes expected penalties for firms. Given the other firm's threshold is $x$, a firm expected penalty from applying for leniency is decreasing in $x$,

$$
-H^{\prime}\left(x \mid s_{1}\right)\left(\frac{1-\theta}{2}\right) F<0
$$

and from not applying for leniency is decreasing in $x$,

$$
-F\left\{1-E\left[\rho \mid s_{1}, s_{2}=x\right]\right\} H^{\prime}\left(x \mid s_{1}\right)<0 .
$$

Thus, for any strategy of this firm, its expected penalty is lower when the other firm's threshold is higher. Its optimal strategy must result in lower expected penalties when $x$ is higher. Hence, firms rank equilibria according to the threshold $x$, and equilibria with higher $x$ are more preferred.

\section{Comparison of Equilibria with Public and Private Sig- nals}

\subsection{Incentives to Apply: Private vs. Public Signals}

With public signals and assuming the other firm does not apply for leniency, a firm prefers to apply iff

$$
E\left[\rho \mid s_{1}, s_{2}\right]-\theta>0 .
$$


Focusing on the Pareto-efficient equilibrium, leniency is used only when the likelihood attached to the CA prosecuting and convicting them exceeds the leniency parameter. Behavior is entirely driven by beliefs as to CA behavior.

By comparison, consider the situation when firms' signals are private. Firm 1 prefers to apply for leniency iff

$$
\underbrace{E\left[\rho \mid s_{1}, s_{2} \leq x\right]-\theta}_{\text {Prosecution effect }}>\underbrace{-\left(\frac{1-\theta}{2}\right)\left[\frac{1-H\left(x \mid s_{1}\right)}{H\left(x \mid s_{1}\right)}\right]}_{\text {Pre-emption effect }}
$$

In contrasting, (9) and (10), first note that the LHS is different, which encompasses what is referred to as the prosecution effect for it is the differential between beliefs as to the CA's probability of successful prosecution (without use of the leniency program) and the leniency parameter. With public signals, the likelihood attached to the CA levying penalties is based on firms' common signals. With private signals, a firm doesn't know its rival's signal and so its expectation is based on its own signal and its rival's signal being sufficiently low so it chooses not to apply. The relationship between these two expectations - $E\left[\rho \mid s_{1}, s_{2}\right]$ and $E\left[\rho \mid s_{1}, s_{2} \leq x\right]-$ is ambiguous. What is not ambiguous is the relationship between the RHS of these two conditions. With private signals, a firm is not assured as to what the other firm will do. Even if firm 1's signal is very low - suggesting that being caught by the CA is unlikely and thus firms should not apply for leniency (i.e., the prosecution effect is weak) - it realizes that firm 2's signal could be high in which case firm 2 would apply. Note that $1-H\left(x \mid s_{1}\right)$ is the probability that a rival applies for leniency conditional on a firm's signal in which case the RHS of (10) is lower, the more likely it is that the other firm will apply for leniency. This provides a second reason for firm 1 to go for amnesty, which is quite independent of whether it thinks the CA will catch them. I refer to it as the pre-emption effect because it captures a firm's concern with its rival applying for leniency prior to the firm having information that would make it preferable for it to apply.

In sum, it is not immediately clear whether information being private makes firms more or less inclined to apply for leniency. While the pre-emption effect is present only with private signals - and clearly serves to enhance the attractiveness of applying for leniency - whether the prosecution effect is stronger or weaker with private signals is not clear at this point.

\subsection{Example 1}

To gain some initial insight into how private information influences behavior, here I consider a specific structure to the signals and derive equilibria under both public and private signals. Assume $\rho=s_{1}+s_{2}$ where $s_{1}$ and $s_{2}$ are independent with a uniform distribution on $[0,1 / 2]$. One might interpret each firm as learning about a particular body of mutually exclusive evidence and, furthermore, the probability the CA convicts is linear in the sum of the evidence. 
With public signals, the Pareto-efficient equilibrium is

$$
\phi\left(s_{1}, s_{2}\right)= \begin{cases}\text { Apply } & \text { if } s_{1}+s_{2}>\theta \\ \text { Do not apply } & \text { if } s_{1}+s_{2} \leq \theta\end{cases}
$$

so the probability of leniency being used is ${ }^{5}$

$$
\operatorname{Pr}\left(s_{1}+s_{2}>\theta\right)= \begin{cases}1-2 \theta^{2} & \text { if } \theta<1 / 2 \\ 2(1-\theta)^{2} & \text { if } \theta \geq 1 / 2\end{cases}
$$

The probability of conviction - which is the probability of at least one firm applying for leniency plus the probability of conviction conditional on no firm applying - equals

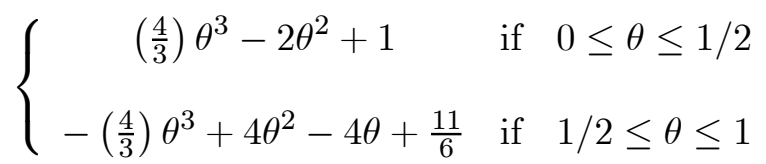

The relationship between the probability of conviction and the leniency parameter is depicted in Figure 1. More leniency (lower $\theta$ ) results in a greater chance of conviction.

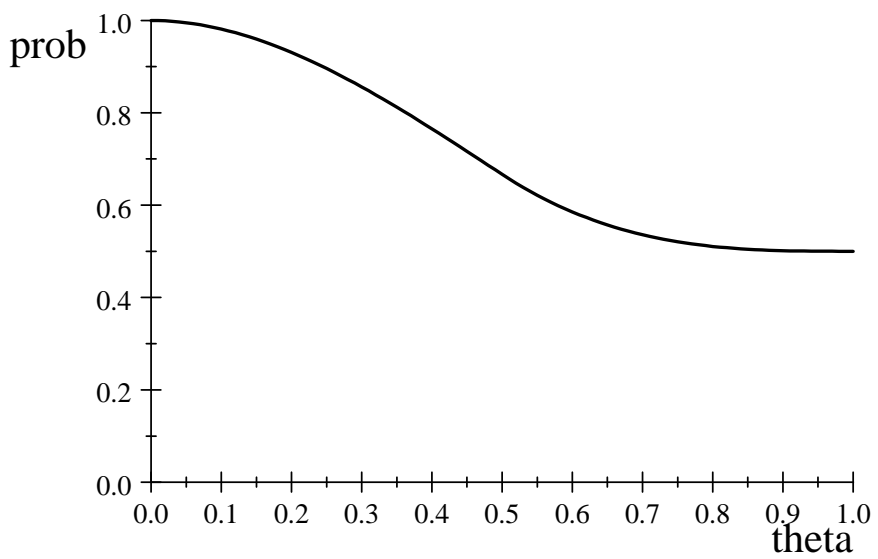

Figure 1: Probability of Conviction (Public Signals)

For when signals are private, the difference between expected penalties from not applying and from applying, given a firm's signal is at the cut-off value, is

$$
\Phi(x)=3 x^{2}-(1+\theta) x+\frac{1-\theta}{2} .
$$

Since $\underline{s}=0$ and $\bar{s}=1 / 2$, recall that: i) $x=0$ is an equilibrium cut-off; ii) if $x \in(0,1 / 2)$ and $\Phi(x)=0$ then $x$ is an equilibrium cut-off; and iii) if $\Phi(1 / 2) \leq 0$ then $x=1 / 2$ is an equilibrium cut-off. If $\theta<\frac{\sqrt{21}-4}{6}$ then $\Phi(x)>0 \forall x$ which implies a unique equilibrium of $x=0$; an example of which is shown in Figure 2 as the dotted

\footnotetext{
${ }^{5}$ This and all ensuing derivations for Example 1 are in Appendix A.
} 
curve. If $\theta=\sqrt{21}-4$ then $\Phi\left(\frac{\sqrt{21}-3}{6}\right)=0$ and $\Phi(x)>0 \forall x \neq \frac{\sqrt{21}-3}{6} \simeq .26$, in which case equilibria are $x \in\left\{0, \frac{\sqrt{21}-3}{36}\right\}$. If $\theta>\sqrt{21}-4$ then $\Phi(x)=0$ has two roots,

$$
\frac{1+\theta-\sqrt{\theta^{2}+8 \theta-5}}{6}, \frac{1+\theta+\sqrt{\theta^{2}+8 \theta-5}}{6} .
$$

The lower root always lies in $(0,1 / 2)$, while the upper root does iff $\theta<3 / 4$. Hence, if $\theta \in\left(\sqrt{21}-4, \frac{3}{4}\right)$ then equilibrium cut-offs are $\left\{0, \frac{1+\theta-\sqrt{\theta^{2}+8 \theta-5}}{6}, \frac{1+\theta+\sqrt{\theta^{2}+8 \theta-5}}{6}\right\}$. This case is depicted as the dashed curve in Figure 2. Finally, if $\theta \in\left[\frac{3}{4}, 1\right)$ then equilibrium cut-offs are $\left\{0, \frac{1+\theta-\sqrt{\theta^{2}+8 \theta-5}}{6}, \frac{1}{2}\right\}$; see the solid curve in Figure 2. With Figure 2, note that $\Phi(x)$ is decreasing in $\theta$ so $\Phi(x)$ shifts down as $\theta$ increases.

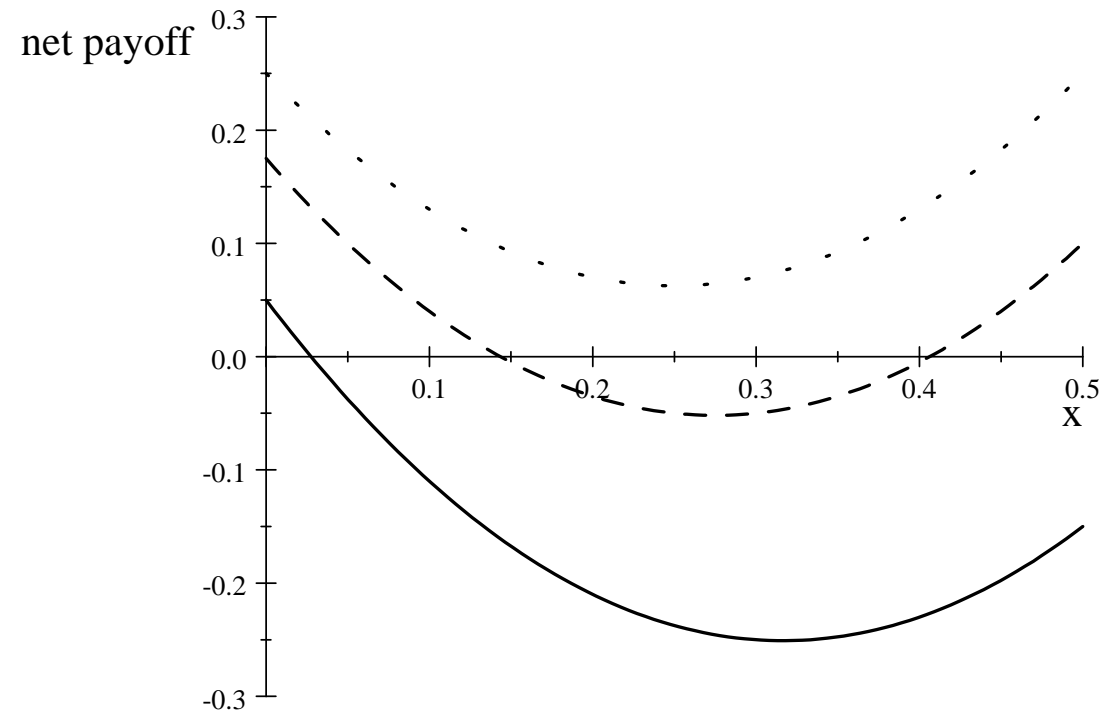

Figure 2: Impact of $\theta$ on $\Phi(x)$

Solid: $\theta=.9$; Dash: $\theta=.6$; Dot: $\theta=.5$

Summing up the preceding analysis, the set of cut-off equilibria with private signals is

$$
\begin{aligned}
& \text { If } \theta \in[0, \sqrt{21}-4) \text { then } x \in\{0\} . \\
& \text { If } \theta=\sqrt{21}-4 \text { then } x \in\left\{0, \frac{\sqrt{21}-3}{36}\right\} . \\
& \text { If } \theta \in\left(\sqrt{21}-4, \frac{3}{4}\right) \text { then } x \in\left\{0, \frac{1+\theta-\sqrt{\theta^{2}+8 \theta-5}}{6}, \frac{1+\theta+\sqrt{\theta^{2}+8 \theta-5}}{6}\right\} . \\
& \text { If } \theta \in\left[\frac{3}{4}, 1\right) \text { then } x \in\left\{0, \frac{1+\theta-\sqrt{\theta^{2}+8 \theta-5}}{6}, \frac{1}{2}\right\} .
\end{aligned}
$$

In Figure 3, the equilibrium correspondence with private signals is plotted (solid line) along with the Pareto-efficient equilibrium under public signals (dashed line). The interior intersection of the two curves occurs at $\theta=2-\sqrt{2} \simeq .586$. 


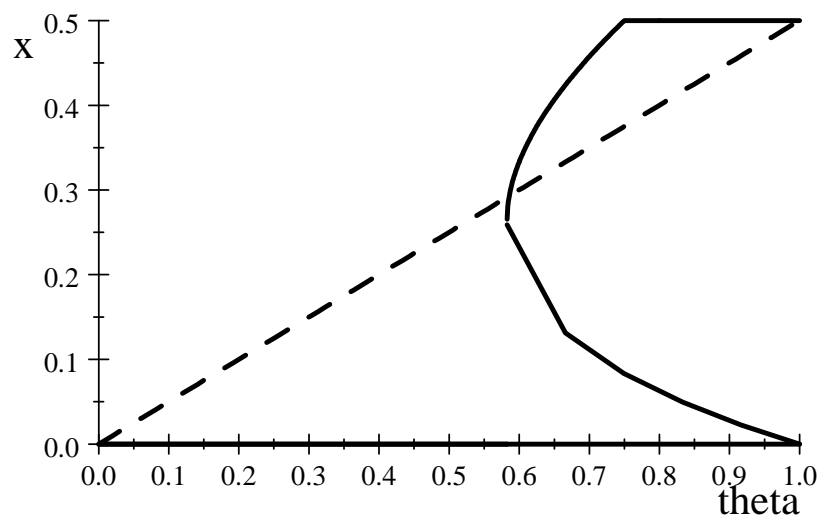

Figure 3: Equilibrium Correspondence Private Signals (Solid), Public Signals (Dashed)

If leniency is sufficiently strong - such as $\theta<\sqrt{21}-4$ - then it is used more with private signals than with public signals. When both firms' signals are low then leniency is not used when signals are public. However, with private signals, even when a firm's signal is low, the probability that the other firm's signal is not low so that it would apply - is high; and if one's rival is very likely to apply for leniency then it is optimal for a firm to do so as well, regardless of its own signal. Hence, with private signals, leniency is always used when leniency is sufficiently great. Intuitively, when leniency means having a high fraction of penalties waived, a firm is going to use leniency unless it believes the CA is unlikely to catch them and it is confident the other firm will not apply. The latter can only be satisfied when signals are public so a firm knows what its rival believes. Note that the probability of being found guilty - which is the sum of the probability of using leniency plus the probability of conviction conditional on not using leniency - is higher as well with private signals.

Now suppose leniency is sufficiently weak: $\theta>2-\sqrt{2}$. Now we find that a firm is more likely to apply for leniency when signals are public rather than private. With a weak leniency program, the inclination is not to apply for leniency unless a firm is confident that the CA will catch them. Such confidence is more likely when firms' signals are public as then there is more information to substantiate the hypothesis that the CA is likely to convict them. With private signals, even if a firm gets a strong signal, it knows that its rival's signal is likely not to be strong and thus there is not sufficient information to warrant applying for leniency. But when signals are public and both of them are consistent with the CA having a strong case, firms will then apply out of fear of being prosecuted. Intuitively, with a weak leniency program, the default is not to apply unless one is confident the CA will catch them or the other firm will apply, and such confidence cannot be achieved when firms' signals are private. Though each firm may be more inclined to apply for leniency when signals are public, it doesn't follow that the probability of being found guilty is higher with public signals for all it takes is one firm to apply for leniency for guilt to 
be established. However, when $\theta \geq 3 / 4$, firms never use leniency with private signals so the probability of being found guilty must be lower.

Next let us compare the probability of conviction between public and private signals, and we'll do so for the Pareto-efficient equilibrium (which means leniency usage is minimized). The probability of conviction for the case of public signals is (12). For when signals are private, the probability of conviction, given cut-off $x$, is

$$
\int_{0}^{x}\left[\int_{0}^{x}\left(s_{1}+s_{2}\right) 2 d s_{2}+1 \times \int_{x}^{1} 2 d s_{2}\right] 2 d s_{1}+\int_{x}^{1 / 2} 1 \times 2 d s_{1}=4 x^{3}-4 x^{2}+1 .
$$

The Pareto-efficient equilibrium value for $x$ is

$$
\left\{\begin{array}{ccc}
0 & \text { if } & 0 \leq \theta<\sqrt{21}-4 \\
\frac{1+\theta+\sqrt{\theta^{2}+8 \theta-5}}{6} & \text { if } & \sqrt{21}-4 \leq \theta \leq .75 \\
.5 & \text { if } & .75 \leq \theta \leq 1
\end{array}\right.
$$

Inserting (14) into (13), the probability of conviction is

$$
\left\{\begin{array}{cccc}
1 & \text { if } & 0 \leq \theta<\sqrt{21}-4 \\
6\left(\frac{1+\theta+\sqrt{\theta^{2}+8 \theta-5}}{6}\right)^{3}-4\left(\frac{1+\theta+\sqrt{\theta^{2}+8 \theta-5}}{6}\right)^{2}+1 & \text { if } & \sqrt{21}-4 \leq \theta \leq .75 \\
& \text { if } & .75 \leq \theta \leq 1
\end{array}\right.
$$

and is depicted in Figure 4.

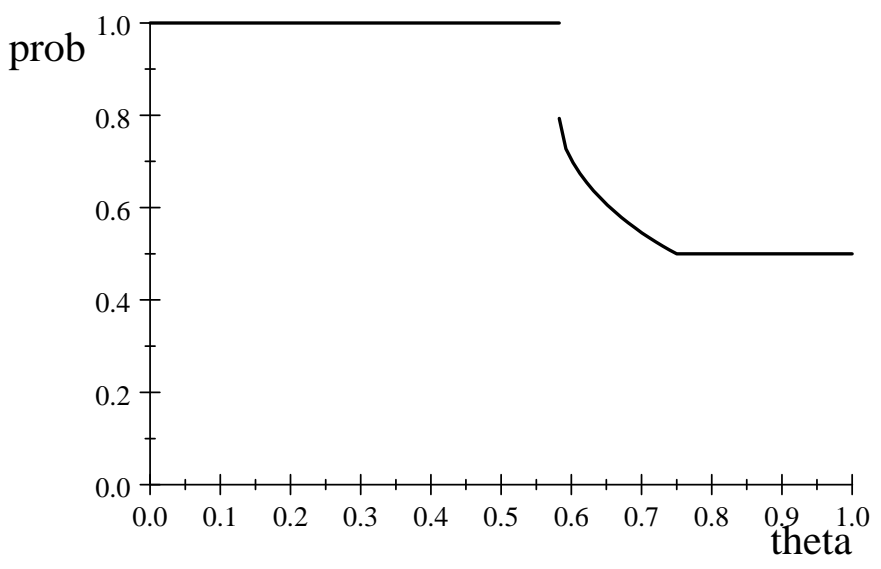

Figure 4: Probability of Conviction (Private Signals)

The difference between the probability of conviction under public signals and under private signals is plotted in Figure 5. Generally, conviction is much more likely under private signals when leniency is sufficiently low $(\theta<.715)$, and is (slightly) 
more likely under public signals when leniency is sufficiently high $(\theta>.715)$.

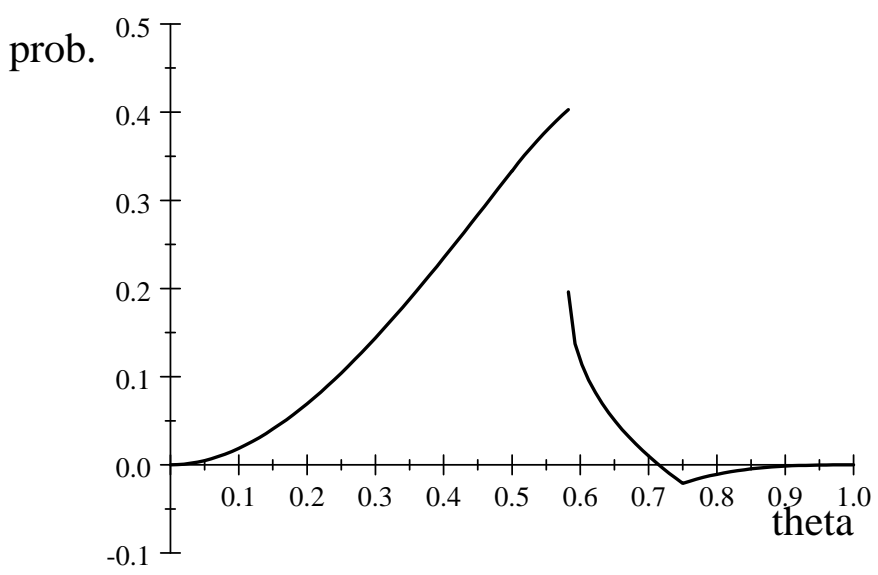

Figure 5: Probability of Conviction under Private Signals minus Probability of Conviction under Public Signals

\subsection{General Results}

In this section, the generality of some of the properties in Example 1 are established. First, it is shown that a leniency program is more effective when firms' signals are private, as long as the program is sufficiently generous. Second, sufficient conditions are provided for a leniency program to be more effective when signals are public.

In Example 1 for when there are private signals, it was found that if $\theta$ is sufficiently low then there is a unique equilibrium in which firms always apply for leniency. Theorem 1 shows the generality of this result.

Theorem 1 For the case of private signals, $\exists \theta^{\prime} \in(0,1)$ such that, $\forall \theta \in\left[0, \theta^{\prime}\right)$, the unique symmetric cut-off Bayes-Nash equilibrium is for firms to apply for leniency for all signals.

Proof. For this theorem to hold, it must be true that

$$
\Phi(x)=\Gamma(x)\left\{E\left[\rho \mid s_{1}=x, s_{2} \leq x\right]-\theta\right\}+\left(\frac{1-\theta}{2}\right)[1-\Gamma(x)]>0, \forall x .
$$

Set $\Phi(x)=0$ and solve for $\theta$ :

$$
\begin{gathered}
\Gamma(x)\left\{E\left[\rho \mid s_{1}=x, s_{2} \leq x\right]-\theta\right\}+\left(\frac{1-\theta}{2}\right)[1-\Gamma(x)]=0 \\
\theta=\frac{1+\Gamma(x)-2 \Gamma(x)\left\{1-E\left[\rho \mid s_{1}=x, s_{2} \leq x\right]\right\}}{1+\Gamma(x)} \equiv \theta^{o}(x) \in(0,1), \forall x \in(\underline{s}, \bar{s}) .
\end{gathered}
$$

Since

$$
\lim _{x \rightarrow \underline{s}} \theta^{o}(x)=1, \lim _{x \rightarrow \bar{s}} \theta^{o}(x)=E\left[\rho \mid s_{1}=\bar{s}\right]>0,
$$


(with the positive inequality due to A2) then

$$
\theta^{o}(x) \in(0,1], \forall x \in[\underline{s}, \bar{s}] .
$$

Since

$$
\frac{\partial \Phi(x)}{\partial \theta}=-\left(\frac{1+\Gamma(x)}{2}\right)<0
$$

then

$$
\Phi(x)>0, \forall \theta \in\left[0, \theta^{o}(x)\right) .
$$

Defining

$$
\theta^{\prime} \equiv \min \left\{\theta^{o}(x): x \in[\underline{s}, \bar{s}]\right\} \in(0,1)
$$

then

$$
\Phi(x)>0, x \in[\underline{s}, \bar{s}], \forall \theta \in\left[0, \theta^{\prime}\right) .
$$

Theorem 1 does not by itself prove that, when leniency is sufficiently generous, the program is used more often with private signals than with public signals. It shows that when $\theta$ is sufficiently low, firms use the leniency program with probability one when signals are private. For usage to exceed that when signals are public, the leniency program must be used with probability less than one when signals are public which is the case only if $\theta>E\left[\rho \mid s_{1}=\underline{s}, s_{2}=\underline{s}\right]$. But then there is the issue of whether, when $\theta>E\left[\rho \mid s_{1}=\underline{s}, s_{2}=\underline{s}\right]$, is $\theta$ low enough for Theorem 1 to apply? To show that is indeed the case, I assume $\Gamma(x)$ is non-decreasing in $x$. This condition, while plausible, is restrictive. A discussion of it is provided in Appendix C, which should only be read after reading the re-formulation of the problem provided in Section $6 .{ }^{6}$

Theorem 2 Assume $\Gamma(x)$ is non-decreasing in $x$. There exists an open interval of values for $\theta$ such that the probability of leniency usage and conviction is higher for all equilibria with private signals than for the Pareto-efficient equilibrium with public signals.

Proof. Consider a value for $\theta$ such that

$$
\left(E\left[\rho \mid s_{1}=\bar{s}, s_{2} \leq \bar{s}\right]=\right) E\left[\rho \mid s_{1}=\bar{s}\right]>\theta>E\left[\rho \mid s_{1}=\underline{s}, s_{2}=\underline{s}\right] .
$$

Next let us show that $E\left[\rho \mid s_{1}=x, s_{2} \leq x\right]$ is increasing in $x$. Let $G$ be the cdf on a firm's signal

$$
E\left[\rho \mid s_{1}=x, s_{2} \leq x\right]=\int_{\underline{s}}^{x} E\left[\rho \mid s_{1}=x, s_{2}\right]\left(\frac{G^{\prime}\left(s_{2}\right)}{G(x)}\right) d s_{2}
$$

\footnotetext{
${ }^{6}$ Recall that $\Gamma(x)$ is the probability that the other firm's signal does not exceed $x$ conditional on one's own signal equalling $x$. In evaluating when $\Gamma(x)=\operatorname{Pr}\left(s_{2} \leq x \mid s_{1}=x\right)$ is non-decreasing in $x$, there are two countervailing forces. To express them, consider $\Gamma(x)=\operatorname{Pr}\left(s_{2} \leq y \mid s_{1}=z\right)$. As $y$ increases, $\operatorname{Pr}\left(s_{2} \leq y \mid s_{1}=z\right)$ is non-decreasing for the obvious reason that a cdf is non-decreasing. But, by A1, a rise in firm 1's signal causes a FOSD shift in the cdf on firm 2's signal which means $\operatorname{Pr}\left(s_{2} \leq y \mid s_{1}=z\right)$ is non-increasing in $z$.
} 


$$
\begin{aligned}
\frac{\partial E\left[\rho \mid s_{1}=x, s_{2} \leq x\right]}{\partial x}= & E\left[\rho \mid s_{1}=x, s_{2}=x\right]\left(\frac{G^{\prime}(x)}{G(x)}\right)+\int_{\underline{s}}^{x}\left(\frac{\partial E\left[\rho \mid s_{1}=x, s_{2}\right]}{\partial s_{1}}\right)\left(\frac{G^{\prime}\left(s_{2}\right)}{G(x)}\right) d s_{2} \\
& -\int_{\underline{s}}^{x} E\left[\rho \mid s_{1}=x, s_{2}\right]\left(\frac{G^{\prime}\left(s_{2}\right) G^{\prime}(x)}{G(x)^{2}}\right) d s_{2} .
\end{aligned}
$$

Since $\partial E\left[\rho \mid s_{1}=x, s_{2}\right] / \partial s_{1}>0$ then $\partial E\left[\rho \mid s_{1}=x, s_{2} \leq x\right] / \partial x>0$ if

$$
\begin{gathered}
E\left[\rho \mid s_{1}=x, s_{2}=x\right]\left(\frac{G^{\prime}(x)}{G(x)}\right)-\int_{\underline{s}}^{x} E\left[\rho \mid s_{1}=x, s_{2}\right]\left(\frac{G^{\prime}\left(s_{2}\right) G^{\prime}(x)}{G(x)^{2}}\right) d s_{2}>0 \Leftrightarrow \\
E\left[\rho \mid s_{1}=x, s_{2}=x\right]-\int_{\underline{s}}^{x} E\left[\rho \mid s_{1}=x, s_{2}\right]\left(\frac{G^{\prime}\left(s_{2}\right)}{G(x)}\right) d s_{2}>0,
\end{gathered}
$$

which is true since $E\left[\rho \mid s_{1}=x, s_{2}\right]$ is increasing in $s_{2}$.

By (15), continuity, and that $E\left[\rho \mid s_{1}=x, s_{2} \leq x\right]$ is increasing in $x$, there exists unique $s^{\prime} \in(\underline{s}, \bar{s})$ defined by

$$
E\left[\rho \mid s_{1}=s^{\prime}, s_{2} \leq s^{\prime}\right]-\theta=0 .
$$

We will show that the theorem holds when $\theta$ satisfies:

$\min \left\{E\left[\rho \mid s_{1}=\bar{s}\right], \frac{2 \Gamma\left(s^{\prime}\right) E\left[\rho \mid s_{1}=\underline{s}, s_{2}=\underline{s}\right]+\left[1-\Gamma\left(s^{\prime}\right)\right]}{\left[1+\Gamma\left(s^{\prime}\right)\right]}\right\}>\theta>E\left[\rho \mid s_{1}=\underline{s}, s_{2}=\underline{s}\right]$.

Hence, leniency is neither too strong nor too weak; $\theta$ should be low enough that leniency is always used when signals are private but high enough so that leniency is not always used when signals are public.

Note that an open set of values for $\theta$ satisfies (17) as

$$
\min \left\{E\left[\rho \mid s_{1}=\bar{s}\right], \frac{2 \Gamma\left(s^{\prime}\right) E\left[\rho \mid s_{1}=\underline{s}, s_{2}=\underline{s}\right]+\left[1-\Gamma\left(s^{\prime}\right)\right]}{\left[1+\Gamma\left(s^{\prime}\right)\right]}\right\}>E\left[\rho \mid s_{1}=\underline{s}, s_{2}=\underline{s}\right]
$$

since

$$
E\left[\rho \mid s_{1}=\bar{s}\right]>E\left[\rho \mid s_{1}=\underline{s}, s_{2}=\underline{s}\right]
$$

and

$$
\frac{2 \Gamma\left(s^{\prime}\right) E\left[\rho \mid s_{1}=\underline{s}, s_{2}=\underline{s}\right]+\left[1-\Gamma\left(s^{\prime}\right)\right]}{\left[1+\Gamma\left(s^{\prime}\right)\right]}>E\left[\rho \mid s_{1}=\underline{s}, s_{2}=\underline{s}\right]
$$

given that the LHS is a weighted average of $E\left[\rho \mid s_{1}=\underline{s}, s_{2}=\underline{s}\right]$ and 1 .

We want to show that if (17) holds then, with private signals, all equilibria have firms applying for leniency for all signals, which requires:

$$
\Phi(x)=\Gamma(x)\left\{E\left[\rho \mid s_{1}=x, s_{2} \leq x\right]-\theta\right\}+\left(\frac{1-\theta}{2}\right)[1-\Gamma(x)]>0, \forall x .
$$

We have that:

$$
\begin{aligned}
& \Phi(\underline{s})=\frac{1-\theta}{2}>0 \\
& \Phi(\bar{s})=E\left[\rho \mid s_{1}=\bar{s}, s_{2} \leq \bar{s}\right]-\theta=E\left[\rho \mid s_{1}=\bar{s}\right]-\theta>0 .
\end{aligned}
$$


with the latter inequality following from (17). From (17),

$$
\frac{2 \Gamma\left(s^{\prime}\right) E\left[\rho \mid s_{1}=\underline{s}, s_{2}=\underline{s}\right]+\left[1-\Gamma\left(s^{\prime}\right)\right]}{\left[1+\Gamma\left(s^{\prime}\right)\right]}>\theta,
$$

which can be re-arranged to

$$
\Gamma\left(s^{\prime}\right)\left\{E\left[\rho \mid s_{1}=\underline{s}, s_{2}=\underline{s}\right]-\theta\right\}+\left(\frac{1-\theta}{2}\right)\left[1-\Gamma\left(s^{\prime}\right)\right]>0 .
$$

Given that $\Gamma(x)$ and $E\left[\rho \mid s_{1}=x, s_{2} \leq x\right]$ are increasing in $x,(19)$ implies

$$
\begin{aligned}
0 & <\Gamma\left(s^{\prime}\right)\left\{E\left[\rho \mid s_{1}=\underline{s}, s_{2}=\underline{s}\right]-\theta\right\}+\left(\frac{1-\theta}{2}\right)\left[1-\Gamma\left(s^{\prime}\right)\right] \\
& <\Gamma\left(s^{\prime}\right)\left\{E\left[\rho \mid s_{1}=x, s_{2} \leq x\right]-\theta\right\}+\left(\frac{1-\theta}{2}\right)\left[1-\Gamma\left(s^{\prime}\right)\right] \\
& \leq \Gamma(x)\left\{E\left[\rho \mid s_{1}=x, s_{2} \leq x\right]-\theta\right\}+\left(\frac{1-\theta}{2}\right)[1-\Gamma(x)], \text { for } x \leq s^{\prime} .
\end{aligned}
$$

The second inequality is true because $E\left[\rho \mid s_{1}=x, s_{2} \leq x\right]$ is increasing in $x$. As to the third inequality, note that (16) and $E\left[\rho \mid s_{1}=x, s_{2} \leq x\right]$ is increasing in $x$ imply $E\left[\rho \mid s_{1}=x, s_{2} \leq x\right]-\theta<0$ for $x<s^{\prime}$. Since $\Gamma\left(s^{\prime}\right)$ is non-decreasing in $s^{\prime}$ then

$$
\Gamma\left(s^{\prime}\right)\left\{E\left[\rho \mid s_{1}=x, s_{2} \leq x\right]-\theta\right\}+\left(\frac{1-\theta}{2}\right)\left[1-\Gamma\left(s^{\prime}\right)\right]
$$

is decreasing in $s^{\prime}$. We then have:

$$
\Gamma(x)\left\{E\left[\rho \mid s_{1}=x, s_{2} \leq x\right]-\theta\right\}+\left(\frac{1-\theta}{2}\right)[1-\Gamma(x)]>0, \text { for } x \leq s^{\prime},
$$

and, therefore, (18) holds for $x \leq s^{\prime}$. When $x>s^{\prime}$ then, from (16) and that $E\left[\rho \mid s_{1}=x, s_{2} \leq x\right]$ is increasing in $x, E\left[\rho \mid s_{1}=x, s_{2} \leq x\right]>\theta$, which implies (18) holds. Hence, the unique equilibrium with private signals is $x=\underline{s}$ which means that leniency is used with probability one, and conviction occurs with probability one.

Now consider the case with public signals. Since we are considering values for $\theta$ such that $\theta>E\left[\rho \mid s_{1}=\underline{s}, s_{2}=\underline{s}\right]$ then a Pareto-efficient equilibrium has leniency not being used for a positive measure of signals. Thus, leniency is used and conviction occurs with probability less than one. Leniency is then used more frequently when signals are private.

The next result presumes the condition

$$
E\left[\rho \mid s_{1}=\bar{s}, s_{2}=\bar{s}\right]>E\left[\rho \mid s_{1}=\bar{s}\right]
$$

which is quite natural if

$$
E\left[\rho \mid s_{1}=\bar{s}\right]>E[\rho],
$$

so that the highest signal causes firms to increase their expectation on $\rho$, and firms' signals are positively but not perfectly correlated. If leniency is sufficiently weak - 
$E\left[\rho \mid s_{1}=\bar{s}\right]<\theta$ - then the Pareto-efficient equilibrium with private signals is to never apply for leniency because, given the other firm does not apply, a firm will prefer not to apply even if it receives the strongest signal. If, in addition, leniency is not too weak - so that $\theta<E\left[\rho \mid s_{1}=\bar{s}, s_{2}=\bar{s}\right]$ - then leniency will be used with positive probability in all equilibria when there are public signals. If both firms receive the strongest signals then this is sufficient to induce usage of the program.

\section{Theorem 3 If}

$$
E\left[\rho \mid s_{1}=\bar{s}, s_{2}=\bar{s}\right]>\theta>E\left[\rho \mid s_{1}=\bar{s}\right]
$$

then the probability of leniency usage and conviction is higher for all equilibria with public signals compared to the Pareto-efficient equilibrium with private signals.

Proof. First note that $E\left[\rho \mid s_{1}=\bar{s}\right]=E\left[\rho \mid s_{1}=\bar{s}, s_{2} \leq \bar{s}\right]$. Hence, $\Phi(\bar{s})=E\left[\rho \mid s_{1}=\bar{s}\right]-$ $\theta>0$. Therefore, $x=\bar{s}$ is an equilibrium with private signals, and leniency is never used. For public signals, since $E\left[\rho \mid s_{1}=\bar{s}, s_{2}=\bar{s}\right]>\theta$ then leniency is used for a positive measure of signals for all equilibria. Hence, leniency usage is greater and the probability of conviction is greater with public signals than with the Pareto-efficient equilibrium with private signals.

In conclusion, the efficacy of a leniency program is neither universally stronger nor weaker when firms have private information as to the ability of the CA to successfully prosecute them, compared to when they have only public information. If the program is sufficiently generous (but not so generous that leniency usage would occur in all cases with public signals) then leniency usage and conviction are more frequent when firms have private information. If the program doesn't provide much leniency then leniency usage and conviction are less frequent with private information. A final distinction worth emphasizing is that if $E\left[\rho \mid s_{1}=\underline{s}, s_{2}=\underline{s}\right]<\theta$, which is a fairly weak condition, firms do not apply for leniency for sure when they have common information. However, when they have private information, if $\theta$ is sufficiently low then they always apply for leniency.

\section{Increasing the Discovery and Prosecution of Cartels}

\subsection{Re-formulation of the Problem}

In this section, we'll explore the effect of a CA being more effective in prosecuting a cartel without one of its members cooperating through the leniency program. To do so, the problem will be reformulated by defining two events, denoted $\mathrm{E}$ and $\mathrm{NE}$. Event $\mathrm{E}$ is the event that the $\mathrm{CA}$ has (or will have) sufficient evidence to convict even if no firm comes forward for leniency. Event NE is the complementary event, so the CA will not be able to convict when no firm cooperates. Let $\gamma$ denote the prior probability attached to event E. $f^{E}(s)$ is the density function on a firm's signal conditional on the CA having sufficient evidence to convict (event E), and $f^{N E}(s)$ is the density function on a firm's signal conditional on the CA not having sufficient evidence to convict. The associated cdfs are $F^{E}$ and $F^{N E}$ and it is assumed $F^{E}$ 
FOSD $F^{N E}$. Thus far, this representation is equivalent to that previously specified. Additional structure is now placed on the problem by assuming that, conditional on event $E$ or $N E$, firms' signals are independent.

$\Delta(x)$ now takes the form

$$
\Delta(x)=\operatorname{Pr}\left[E \mid s_{1}=x, s_{2} \leq x\right]-\theta+\left(\frac{1-\theta}{2}\right)\left[\frac{1-\Gamma(x)}{\Gamma(x)}\right]
$$

where $\operatorname{Pr}\left[E \mid s_{1}=x, s_{2} \leq x\right]$ substitutes for $E\left[\rho \mid s_{1}=x, s_{2} \leq x\right] .{ }^{7}$ Where we can use the assumption of conditional independence is in deriving an expression for $\Gamma(x)$. First note that

$$
\Gamma(x)=\operatorname{Pr}\left(s_{2} \leq x \mid s_{1}=x\right)=\operatorname{Pr}\left(s_{2} \leq x, E \mid s_{1}=x\right)+\operatorname{Pr}\left(s_{2} \leq x, N E \mid s_{1}=x\right) .
$$

Given firms' signals are conditionally independent then

$$
\operatorname{Pr}\left(s_{2} \leq x, E \mid s_{1}=x\right)=\operatorname{Pr}\left(E \mid s_{1}=x\right) \operatorname{Pr}\left(s_{2} \leq x \mid E\right)
$$

and

$$
\operatorname{Pr}\left(s_{2} \leq x, N E \mid s_{1}=x\right)=\operatorname{Pr}\left(N E \mid s_{1}=x\right) \operatorname{Pr}\left(s_{2} \leq x \mid N E\right)
$$

Inserting (23) and (22) into (21),

$$
\begin{aligned}
\Gamma(x) & =\operatorname{Pr}\left(E \mid s_{1}=x\right) \operatorname{Pr}\left(s_{2} \leq x \mid E\right)+\operatorname{Pr}\left(N E \mid s_{1}=x\right) \operatorname{Pr}\left(s_{2} \leq x \mid N E\right) \\
& =\left(\frac{\gamma f^{E}(x)}{\gamma f^{E}(x)+(1-\gamma) f^{N E}(x)}\right) F^{E}(x)+\left(\frac{(1-\gamma) f^{N E}(x)}{\gamma f^{E}(x)+(1-\gamma) f^{N E}(x)}\right) F^{N E}(x) .
\end{aligned}
$$

Next, we can derive $\operatorname{Pr}\left(E \mid s_{1}=x, s_{2} \leq x\right)$. Note that

$$
\operatorname{Pr}\left(E \mid s_{1}=x, s_{2} \leq x\right)=\frac{\operatorname{Pr}\left(E, s_{1}=x, s_{2} \leq x\right)}{\operatorname{Pr}\left(s_{1}=x, s_{2} \leq x\right)}
$$

and

$$
\begin{aligned}
\operatorname{Pr}\left(E, s_{1}=x, s_{2} \leq x\right) & =\operatorname{Pr}(E) \operatorname{Pr}\left(s_{1}, s_{2} \leq x \mid E\right)=\operatorname{Pr}(E) \operatorname{Pr}\left(s_{1} \mid E\right) \operatorname{Pr}\left(s_{2} \leq x \mid E\right) \\
& =\gamma f^{E}(x) F^{E}(x)
\end{aligned}
$$

and

$$
\begin{aligned}
\operatorname{Pr}\left(s_{1}=x, s_{2} \leq x\right) & =\operatorname{Pr}\left(s_{1}=x, s_{2} \leq x, E\right)+\operatorname{Pr}\left(s_{1}=x, s_{2} \leq x, N E\right) \\
& =\gamma f^{E}(x) F^{E}(x)+\gamma f^{N E}(x) F^{N E}(x)
\end{aligned}
$$

and, therefore,

$$
\operatorname{Pr}\left(E \mid s_{1}=x, s_{2} \leq x\right)=\frac{\gamma f^{E}(x) F^{E}(x)}{\gamma f^{E}(x) F^{E}(x)+(1-\gamma) f^{N E}(x) F^{N E}(x)} .
$$

\footnotetext{
${ }^{7}$ It can be shown that if $f^{E}(s) / f^{N E}(s)$ is increasing in $s$ (i.e., the Monotone Likelihood Ratio Property holds) then $\operatorname{Pr}\left(E \mid s_{1}=x, s_{2} \leq x\right)$ is increasing in $x$.
} 


\subsection{Comparative Static on the Probability of Successful Prosecution}

Suppose the CA is more aggressive in discovering and prosecuting cartels, as reflected in a higher value for $\gamma$, which recall is the probability that it can convict without a leniency applicant. Define $x^{*}$ as the maximal equilibrium:

$$
x^{*}= \begin{cases}\underline{s} & \text { if } \Phi(x)>0, \forall x \in[\underline{s}, \bar{s}] \\ \max \{x: \Phi(x)=0\} & \text { if } \exists x \in(\underline{s}, \bar{s}) \text { s.t. } \Phi(x) \leq 0 \text { and } \Phi(\bar{s})>0 \\ \bar{s} & \text { if } \Phi(\bar{s}) \leq 0 .\end{cases}
$$

The next result shows that if the CA invests more resources in discovery and prosecution then this will induce greater use of the leniency program for the Pareto-efficient equilibrium.

Theorem 4 If $x^{*} \in(\underline{s}, \bar{s})$ then, generically, $\frac{\partial x^{*}}{\partial \gamma}<0$.

Proof. If $x^{*} \in(\underline{s}, \bar{s})$ then $\Delta(x) \geq 0$ as $x \geq x^{*}$, and, generically,

$$
\Delta(x) \gtreqless 0 \text { as } x \gtreqless x^{*}, x \in\left[x^{*}-\varepsilon, 1\right] \text { for some } \varepsilon>0 \text {. }
$$

By the differentiability of $\Delta(x)$, this implies $\partial \Delta\left(x^{*}\right) / \partial x>0$. Take the total derivative of $\Delta\left(x^{*}\right)=0$ with respect to $\gamma$ :

$$
\left(\frac{\partial \Delta\left(x^{*}\right)}{\partial x}\right)\left(\frac{\partial x^{*}}{\partial \gamma}\right)+\frac{\partial \Delta\left(x^{*}\right)}{\partial \gamma}=0 \Rightarrow \frac{\partial x^{*}}{\partial \gamma}=-\frac{\partial \Delta\left(x^{*}\right) / \partial \gamma}{\partial \Delta\left(x^{*}\right) / \partial x}
$$

Therefore,

$$
\text { if } \frac{\partial \Delta\left(x^{*}\right)}{\partial \gamma}>0 \text { then } \frac{\partial x^{*}}{\partial \gamma}<0
$$

Consider

$$
\frac{\partial \Delta(x)}{\partial \gamma}=\frac{\partial \operatorname{Pr}\left[E \mid s_{1}=x, s_{2} \leq x\right]}{\partial \gamma}-\left(\frac{1-\theta}{2}\right)\left[\frac{\partial \Gamma(x) / \partial \gamma}{\Gamma(x)^{2}}\right] .
$$

Since

$$
\begin{aligned}
\frac{\partial \Gamma(x)}{\partial \gamma}= & \left(\frac{1}{\gamma f^{E}(x)+(1-\gamma) f^{N E}(x)}\right)^{2} \times \\
& \left\{\left[f^{E}(x) F^{E}(x)-f^{N E}(x) F^{N E}(x)\right]\left[\gamma f^{E}(x)+(1-\gamma) f^{N E}(x)\right]\right. \\
& \left.-\left[\gamma f^{E}(x) F^{E}(x)+(1-\gamma) f^{N E}(x) F^{N E}(x)\right]\left[f^{E}(x)-f^{N E}(x)\right]\right\}
\end{aligned}
$$

then

$$
\begin{aligned}
\operatorname{sign}\left\{\frac{\partial \Gamma(x)}{\partial \gamma}\right\}= & \operatorname{sign}\left\{\gamma f^{E}(x)^{2} F^{E}(x)-\gamma f^{E}(x) f^{N E}(x) F^{N E}(x)+(1-\gamma) f^{N E}(x) f^{E}(x) F^{E}(x)\right. \\
& -(1-\gamma) f^{N E}(x)^{2} F^{N E}(x)-\gamma f^{E}(x)^{2} F^{E}(x)-(1-\gamma) f^{E}(x) f^{N E}(x) F^{N E}(x) \\
& \left.+\gamma f^{N E}(x) f^{E}(x) F^{E}(x)+(1-\gamma) f^{N E}(x)^{2} F^{N E}(x)\right\} \\
= & \operatorname{sign}\left\{-f^{N E}(x) f^{E}(x)\left[F^{N E}(x)-F^{E}(x)\right]\right\} \leq 0
\end{aligned}
$$


as $F^{E}(x)$ FOSD $F^{N E}(x)$. Hence, the second term in (24) is non-negative.

Next consider

$$
\begin{aligned}
& \frac{\partial \operatorname{Pr}\left(E \mid s_{1}=x, s_{2} \leq x\right)}{\partial \gamma} \\
= & {\left[\frac{1}{\gamma f^{E}(x) F^{E}(x)+(1-\gamma) f^{N E}(x) F^{N E}(x)}\right]^{2} \times } \\
& \left\{f^{E}(x) F^{E}(x)\left[\gamma f^{E}(x) F^{E}(x)+(1-\gamma) f^{N E}(x) F^{N E}(x)\right]\right. \\
& \left.-\gamma f^{E}(x) F^{E}(x)\left[f^{E}(x) F^{E}(x)-f^{N E}(x) F^{N E}(x)\right]\right\} \\
= & {\left[\frac{1}{\gamma f^{E}(x) F^{E}(x)+(1-\gamma) f^{N E}(x) F^{N E}(x)}\right]^{2} \times } \\
& \left\{(1-\gamma) f^{E}(x) F^{E}(x) f^{N E}(x) F^{N E}(x)+\gamma f^{E}(x) F^{E}(x) f^{N E}(x) F^{N E}(x)\right\} \\
> & 0
\end{aligned}
$$

Therefore, (24) is positive.

By Theorem 5, more aggressive discovery and prosecution of non-leniency cases will induce greater usage of the leniency program as reflected in firms applying for leniency with weaker signals. Next consider the effect of more aggressive non-leniency enforcement on the probability of conviction,

$$
\gamma+(1-\gamma)\left[1-F^{N E}\left(x^{*}(\gamma)\right)^{2}\right]
$$

Conviction takes place when the CA's case is sufficiently strong (even without leniency), which occurs with probability $\gamma$, and when the CA's case is weak but at least one firm chose to apply for leniency, which is the second term in (25). Taking the total derivative of $(25)$ with respect to $\gamma$,

$\frac{\partial\left\{\gamma+(1-\gamma)\left[1-F^{N E}\left(x^{*}(\gamma)\right)^{2}\right]\right\}}{\partial \gamma}=F^{N E}\left(x^{*}\right)^{2}-2(1-\gamma) F^{N E}\left(x^{*}\right) f^{N E}\left(x^{*}\right)\left(\frac{\partial x^{*}}{\partial \gamma}\right)$.

Raising $\gamma$ has two effects. First, there is a direct effect measured by $F^{N E}\left(x^{*}\right)^{2}$. When $\gamma$ increases, there is a one-to-one increase in the fraction of cartels convicted through non-leniency means. As a fraction $1-F^{N E}\left(x^{*}(\gamma)\right)^{2}$ of them would have been convicted anyway, because they would have applied for leniency, the net effect is $F^{N E}\left(x^{*}(\gamma)\right)^{2}$. Second, there is an indirect effect by raising the usage of the leniency program, which is the second term in (26). Note that

$$
\frac{\partial x^{*}}{\partial \gamma}=-\frac{\left[\frac{\partial \operatorname{Pr}\left(E \mid s_{1}=x^{*}, s_{2} \leq x^{*}\right)}{\partial \gamma}+\left(\frac{1-\theta}{2}\right) \frac{\partial\left(\frac{1-\Gamma\left(x^{*}\right)}{\Gamma\left(x^{*}\right)}\right)}{\partial \gamma}\right]}{\frac{\partial \Delta\left(x^{*}\right)}{\partial x}} .
$$

Embodied in this term are two effects: the change in the prosecution effect,

$$
\frac{\partial \operatorname{Pr}\left(E \mid s_{1}=x^{*}, s_{2} \leq x^{*}\right)}{\partial \gamma},
$$


and the change in the pre-emption effect,

$$
\frac{\partial\left(\frac{1-\theta}{2}\right)\left(\frac{1-\Gamma\left(x^{*}\right)}{\Gamma\left(x^{*}\right)}\right)}{\partial \gamma} .
$$

It is informative to contrast this analysis with when firms lack private information. For the Pareto-efficient equilibrium with public signals, the probability of conviction is

$$
\gamma+(1-\gamma) \operatorname{Pr}\left(\operatorname{Pr}\left(E \mid s_{1}, s_{2}\right)>\theta \mid N E\right) .
$$

With probability $\gamma$, the cartel is convicted with or without leniency as the CA's case is strong. With probability $1-\gamma$, the cartel is only convicted if they apply for leniency which requires that $\operatorname{Pr}\left(E \mid s_{1}, s_{2}\right)>\theta$, which occurs with probability $\operatorname{Pr}\left(\operatorname{Pr}\left(E \mid s_{1}, s_{2}\right)>\theta \mid N E\right)$ given event NE. Evaluate the effect of $\gamma$ on the probability of conviction:

$$
\begin{aligned}
\frac{\partial\left\{\gamma+(1-\gamma) \operatorname{Pr}\left(\operatorname{Pr}\left(E \mid s_{1}, s_{2}\right)>\theta \mid N E\right)\right\}}{\partial \gamma}= & 1-\operatorname{Pr}\left(\operatorname{Pr}\left(E \mid s_{1}, s_{2}\right)>\theta \mid N E\right) \\
& +(1-\gamma) \frac{\partial \operatorname{Pr}\left(\operatorname{Pr}\left(E \mid s_{1}, s_{2}\right)>\theta \mid N E\right)}{\partial \gamma} .
\end{aligned}
$$

Again, more aggressive non-leniency enforcement has two effects on the likelihood of conviction. The direct effect is $1-\operatorname{Pr}\left(\operatorname{Pr}\left(E \mid s_{1}, s_{2}\right)>\theta \mid N E\right)$, and captures the substitution of event $\mathrm{E}$ for event $\mathrm{NE}$, when firms do not apply for leniency. The second effect captures more frequent use of the leniency program when, in fact, the CA's case is weak. Note that

$$
\operatorname{Pr}\left(E \mid s_{1}, s_{2}\right)=\frac{\gamma f^{E}\left(s_{1}\right) f^{E}\left(s_{2}\right)}{\gamma f^{E}\left(s_{1}\right) f^{E}\left(s_{2}\right)+(1-\gamma) f^{N E}\left(s_{1}\right) f^{N E}\left(s_{2}\right)}
$$

is increasing in $\gamma$. Thus, for any pair of signals $\left(s_{1}, s_{2}\right), \operatorname{Pr}\left(E \mid s_{1}, s_{2}\right)$ is higher which implies

$$
\operatorname{Pr}\left(\frac{\gamma f^{E}\left(s_{1}\right) f^{E}\left(s_{2}\right)}{\gamma f^{E}\left(s_{1}\right) f^{E}\left(s_{2}\right)+(1-\gamma) f^{N E}\left(s_{1}\right) f^{N E}\left(s_{2}\right)}>\theta \mid N E\right)
$$

is higher. (Changing $\gamma$ does not alter the distribution on $\left(s_{1}, s_{2}\right)$ conditional on NE.) Since firms' prior probability that the CA's case is strong is higher, their posterior probability is more likely to be higher so that they prefer to apply for leniency. This is the prosecution effect in that more active non-leniency enforcement induces more frequent use of the leniency program. There is, of course, no pre-emption effect.

Finally, analogous to Theorem 1, it can be shown that if the CA is sufficiently effective in discovering and convicting cartels without leniency then, with private 
information, firms will apply for leniency for sure. Note that

$$
\begin{aligned}
& \Delta(x)= \operatorname{Pr}\left[E \mid s_{1}=x, s_{2} \leq x\right]-\theta+\left(\frac{1-\theta}{2}\right)\left[\frac{1-\Gamma(x)}{\Gamma(x)}\right] \\
&= \frac{\gamma f^{E}(x) F^{E}(x)}{\gamma f^{E}(x) F^{E}(x)+(1-\gamma) f^{N E}(x) F^{N E}(x)}-\theta \\
&+\left(\frac{1-\theta}{2}\right)\left[1-\frac{\gamma f^{E}(x) F^{E}(x)+(1-\gamma) f^{N E}(x) F^{N E}(x)}{\gamma f^{E}(x)+(1-\gamma) f^{N E}(x)}\right] \\
& \times\left[\frac{\gamma f^{E}(x)+(1-\gamma) f^{N E}(x)}{\gamma f^{E}(x) F^{E}(x)+(1-\gamma) f^{N E}(x) F^{N E}(x)}\right] \\
&=\frac{\gamma f^{E}(x) F^{E}(x)}{\gamma f^{E}(x) F^{E}(x)+(1-\gamma) f^{N E}(x) F^{N E}(x)}-\theta \\
&+\left(\frac{1-\theta}{2)}\left[\frac{\gamma f^{E}(x)+(1-\gamma) f^{N E}(x)-\gamma f^{E}(x) F^{E}(x)-(1-\gamma) f^{N E}(x) F^{N E}(x)}{\gamma f^{E}(x) F^{E}(x)+(1-\gamma) f^{N E}(x) F^{N E}(x)}\right]\right. \\
&=\frac{\gamma f^{E}(x) F^{E}(x)}{\gamma f^{E}(x) F^{E}(x)+(1-\gamma) f^{N E}(x) F^{N E}(x)}-\theta \\
&+\left(\frac{1-\theta}{2}\right)\left[\frac{\gamma f^{E}(x)\left[1-F^{E}(x)\right]+(1-\gamma) f^{N E}(x)\left[1-F^{N E}(x)\right]}{\gamma f^{E}(x) F^{E}(x)+(1-\gamma) f^{N E}(x) F^{N E}(x)}\right]
\end{aligned}
$$

Since

$$
\lim _{\gamma \rightarrow 1} \Delta(x)=1+\left(\frac{1-\theta}{2}\right)\left(\frac{1-F^{E}(x)}{F^{E}(x)}\right)>0,
$$

then, $\exists \gamma^{\prime}<1$ such that if $\gamma>\gamma^{\prime}$ then the unique Bayes-Nash equilibrium is for a firm to apply for all signals.

\subsection{Example 2}

Consider the following assumptions: ${ }^{8}$

$$
\begin{aligned}
f^{E}(s) & =2 s, F^{E}(s)=s^{2} \\
f^{N E}(s) & =2(1-s), F^{N E}(s)=s(2-s)
\end{aligned}
$$

The density functions on signals are linear. When the CA has enough evidence to convict (event E), the density function assigns higher probability to higher signals; while if the CA does not have enough evidence to convict (event NE), the density function assigns lower probability to higher signals. For this case, the probability of conviction with private signals and with public signals are derived in Appendix B.

Figures 6 and 7 plot the relationship between the probability of conviction and the enforcement parameter $\gamma$, and does so for various values of the leniency parameter $\theta$.

\footnotetext{
${ }^{8}$ I thank Faruk Gul for suggesting this example.
} 
The case of public signals is depicted in Figure 6. As $\gamma$ increases, the probability of conviction rises, not surprisingly. However, note that there is a concave relationship, so the marginal effect of $\gamma$ on the likelihood of conviction is declining with the level of enforcement. There is a crowding out effect with increased enforcement because some situations for which the CA previously had a weak case (and now has a strong case because $\gamma$ is higher) would have still led to a conviction because of the leniency program. Indeed, it is possible that the rise in the probability of conviction can be less than the rise in $\gamma$. For example, when $\theta=.5$, a rise in $\gamma$ by from .7 to .8 raises the probability of conviction by only .091. The concave relationship shows that the crowding out effect increases with the level of enforcement.

Figure 7 depicts the case with private signals. Now, there is generally a convex relationship between the probability of conviction and $\gamma$, with some exceptions occurring when $\theta$ and $\gamma$ are both high. For example, when $\theta=.5$, as the enforcement parameter $\gamma$ rises from .2 to .3 to .4 , the probability of conviction rises from .251 to .398 (an increase of .135) to .553 (a higher increase of .147). While there is a crowding out effect here as well, there is also a multiplier effect between the prosecution and pre-emption effects. With a higher value of $\gamma$, a firm is more inclined to apply because of the prosecution effect. Furthermore, because this means its rival is more inclined to apply, a firm is more inclined to do so out of fear of being pre-empted. There is then a feedback loop: higher $\gamma$ causes firm 1 to be more likely to apply for leniency which makes it more likely firm 2 will apply which makes it more likely firm 1 will apply and so forth. This multiplier effect is not present when firms have public information and is responsible for the marginal effect of increased enforcement rising with the level of enforcement.

\section{Concluding Remarks}

There is more work to be done with this model. Some of the effects found for examples - such as the more high powered effect of increasing enforcement when there are private signals (shown in Example 2) - I want to show more generally. Also of interest is to consider various ways in which the competition authority can accentuate the pre-emption effect and promote usage of the leniency program. For example, if the competition authority has its own signal, should it keep it private? make it public? reveal it to just one of the firms? Another avenue to pursue is whether the competition authority should be more pro-active in encouraging leniency applications. All previous research, including the current paper, assumes the competition authority sits back and waits for leniency applicants to arrive. That is, of course, the only option when it is not suspicious about the presence of a cartel. But there are many cases in which a leniency applicant comes forward after the competition authority already has some information which leads it to suspect there is a cartel. In the latter situation, a more pro-active policy would be to approach one of the firms and offer them leniency. In considering this offer, the firm is uncertain whether the competition authority approached it first - in which case declining the offer would mean the competition authoirity giving its rival the change to apply for leniency - or approached its rival 
first who then declined, which would convey information about its signal. Thinking up other tactical moves by the competition authority - and then exploring them within the model of this paper - could ultimately lead to more effective enforcement of the laws prohibiting cartels.

\section{Appendix A: Example 1}

Assume $\rho=s_{1}+s_{2}$ where $s_{i} \sim U[0,1 / 2]$ and $s_{1}$ and $s_{2}$ are independent with a uniform distribution on $[0,1 / 2]$. If signals are public, the probability of using leniency is $\operatorname{Pr}\left(s_{1}+s_{2}>\theta\right)$. If $t \leq 1 / 2$ then

$$
\operatorname{Pr}\left(s_{1}+s_{2}=t\right)=\int_{0}^{t} \operatorname{Pr}\left(s_{2}=t-s_{1}\right) \operatorname{Pr}\left(s_{1}\right) d s_{1}=\int_{0}^{t}(2 * 2) d s_{1}=4 t,
$$

while if $t>1 / 2$ then

$$
\begin{aligned}
\operatorname{Pr}\left(s_{1}+s_{2}=t\right) & =\int_{0}^{t} \operatorname{Pr}\left(s_{2}=t-s_{1}\right) \operatorname{Pr}\left(s_{1}\right) d s_{1} \\
& =\int_{0}^{t-1 / 2} \operatorname{Pr}\left(s_{2}=t-s_{1}\right) \operatorname{Pr}\left(s_{1}\right) d s_{1}+\int_{t-1 / 2}^{1 / 2} \operatorname{Pr}\left(s_{2}=t-s_{1}\right) \operatorname{Pr}\left(s_{1}\right) d s_{1} \\
& =\int_{0}^{t-1 / 2} 0 * 2 d s_{1}+\int_{t-1 / 2}^{1 / 2}(2 * 2) d s_{1} \\
& \left.=\int_{t-1 / 2}^{1 / 2}(2 * 2) d s_{1}=4 s_{1}\right]_{t-1 / 2}^{1 / 2}=2-4 t+2=4(1-t) .
\end{aligned}
$$

Therefore,

$$
\operatorname{Pr}\left(s_{1}+s_{2}=t\right)= \begin{cases}4 t & \text { if } t<1 / 2 \\ 4(1-t) & \text { if } t \geq 1 / 2\end{cases}
$$

If $\theta \geq 1 / 2$ then

$$
\begin{aligned}
\operatorname{Pr}\left(s_{1}+s_{2} \leq \theta\right) & =\int_{0}^{1 / 2} 4 t d t+\int_{1 / 2}^{\theta} 4(1-t) d t \\
& \left.=2 t^{2}\right]_{0}^{1 / 2}+\int_{1 / 2}^{\theta} 4(1-t) d t \\
& \left.=1 / 2+4 t-2 t^{2}\right]_{1 / 2}^{\theta}=1 / 2+4 \theta-2 \theta^{2}-2+1 / 2 \\
& =-2 \theta^{2}+4 \theta-1=2 \theta^{2}-4 \theta^{2}+4 \theta-1=2 \theta^{2}-(2 \theta-1)^{2} \\
& \operatorname{Pr}\left(s_{1}+s_{2} \leq \theta\right)= \begin{cases}2 \theta^{2} & \text { if } \theta<1 / 2 \\
2 \theta^{2}-(2 \theta-1)^{2} & \text { if } \theta \geq 1 / 2\end{cases}
\end{aligned}
$$

Thus, the probability of using leniency is

$$
\operatorname{Pr}\left(s_{1}+s_{2}>\theta\right)= \begin{cases}1-2 \theta^{2} & \text { if } \theta<1 / 2 \\ 2(1-\theta)^{2} & \text { if } \theta \geq 1 / 2\end{cases}
$$


If $0 \leq \theta \leq 1 / 2$ then the probability of conviction is

$$
\begin{aligned}
& \int_{0}^{\theta}\left[\int_{0}^{\theta-s_{1}}\left(s_{1}+s_{2}\right) 2 d s_{2}+\int_{\theta-s_{1}}^{1 / 2} 1 \times 2 d s_{2}\right] 2 d s_{1}+\int_{\theta}^{1 / 2} 1 \times 2 d s_{1} \\
= & \left(\frac{4}{3}\right) \theta^{3}-2 \theta^{2}+1
\end{aligned}
$$

and, if $1 / 2<\theta \leq 1$, it takes the value

$$
\begin{aligned}
& \int_{0}^{\theta-1 / 2} \int_{0}^{1 / 2}\left(s_{1}+s_{2}\right) 2 d s_{2} 2 d s_{1}+\int_{\theta-1 / 2}^{1 / 2}\left[\int_{0}^{\theta-s_{1}}\left(s_{1}+s_{2}\right) 2 d s_{2}+\int_{\theta-s_{1}}^{1 / 2} 1 \times 2 d s_{2}\right] 2 d s_{1} \\
= & -\left(\frac{4}{3}\right) \theta^{3}+4 \theta^{2}-4 \theta+\frac{11}{6}
\end{aligned}
$$

Hence, the probability of conviction is

$$
\left\{\begin{array}{ccc}
\left(\frac{4}{3}\right) \theta^{3}-2 \theta^{2}+1 & \text { if } & 0 \leq \theta \leq .5 \\
-\left(\frac{4}{3}\right) \theta^{3}+4 \theta^{2}-4 \theta+\frac{11}{6} & \text { if } & .5 \leq \theta \leq 1
\end{array}\right.
$$

For when signals are private, the difference between expected penalties from not applying and from applying, given a firm's signal is at the cut-off value, is

$$
\begin{aligned}
\Phi(x) & =\Gamma(x)\left(E\left[\rho \mid s_{1}=x, s_{2} \leq x\right]-\theta\right)+\left(\frac{1-\theta}{2}\right)[1-\Gamma(x)] \\
& =\Gamma(x)\left(x+E\left[s_{2} \mid s_{2} \leq x\right]-\theta\right)+\left(\frac{1-\theta}{2}\right)[1-\Gamma(x)] \\
& =2 x\left(x+\frac{x}{2}-\theta\right)+\left(\frac{1-\theta}{2}\right)(1-2 x)=3 x^{2}-2 x \theta+\frac{1-\theta}{2}-(1-\theta) x \\
& =3 x^{2}-2 x \theta+\frac{1-\theta}{2}-(1-\theta) x=3 x^{2}-(1+\theta) x+\frac{1-\theta}{2} .
\end{aligned}
$$

Since $\underline{s}=0$ and $\bar{s}=1 / 2$, recall that: i) $x=0$ is an equilibrium; ii) if $x \in(0,1 / 2)$ and $\Phi(x)=0$ then $x$ is an equilibrium cut-off; and iii) if $\Phi(1 / 2) \leq 0$ then $x=1 / 2$ is an equilibrium cut-off.

To derive the set of equilibria, begin by deriving some properties of $\Phi(x)$. It is convex in $x$ and reaches its minimum at $x=\frac{1+\theta}{6}$.

$$
\Phi^{\prime}(x)=6 x-1-\theta \gtreqless 0 \text { as } x \gtreqless \frac{1+\theta}{6} .
$$

Hence, if

$$
\Phi\left(\frac{1+\theta}{6}\right)>0
$$

then $\Phi$ is always positive in which case the unique equilibrium is $x=0$. If

$$
\Phi\left(\frac{1+\theta}{6}\right)<0
$$


then there exists at least one interior equilibrium and $x>0$ for the Pareto-efficient equilibrium. To evaluate which of these cases holds, consider:

$$
\begin{aligned}
\Phi\left(\frac{1+\theta}{6}\right) & =3\left(\frac{1+\theta}{6}\right)^{2}-(1+\theta)\left(\frac{1+\theta}{6}\right)+\frac{1-\theta}{2} \\
& =\frac{(1+\theta)^{2}}{12}-\frac{(1+\theta)^{2}}{6}+\frac{1-\theta}{2}=-\frac{(1+\theta)^{2}}{12}+\frac{1-\theta}{2} \\
& =(1 / 12)\left[-(1+\theta)^{2}+6(1-\theta)\right]=12\left[-1-2 \theta-\theta^{2}+6-6 \theta\right] \\
& =(1 / 12)\left(-\theta^{2}-8 \theta+5\right)
\end{aligned}
$$

Solving this quadratic,

$$
\Phi\left(\frac{1+\theta}{6}\right) \gtreqless 0 \text { as } \theta \lesseqgtr \sqrt{21}-4 \simeq .58, \text { for } \theta \in[0,1] .
$$

From the preceding analysis, if $\theta<\frac{\sqrt{21}-4}{6}$ then $\Phi(x)$ is positive at its minimum value; hence, $\Phi(x)>0 \forall x$ which implies a unique equilibrium of $x=0$. If $\theta=\sqrt{21}-4$ then $\Phi\left(\frac{\sqrt{21}-3}{6}\right)=0$ and $\Phi(x)>0 \forall x \neq \frac{\sqrt{21}-3}{6} \simeq .26$, in which case equilibria are $x \in\left\{0, \frac{\sqrt{21}-3}{36}\right\}$. If $\theta>\sqrt{21}-4$ then $\Phi(x)=0$ has two roots,

$$
\frac{1+\theta-\sqrt{\theta^{2}+8 \theta-5}}{6}, \frac{1+\theta+\sqrt{\theta^{2}+8 \theta-5}}{6} .
$$

Note that the lower root is decreasing in $\theta$ and the upper root is increasing in $\theta$ :

$$
\begin{gathered}
\frac{\partial \frac{1+\theta-\sqrt{\theta^{2}+8 \theta-5}}{6}}{\partial \theta}=\left(\frac{1}{6}\right)\left[1-\frac{1}{2}\left(\theta^{2}+8 \theta-5\right)^{-\frac{1}{2}}(2 \theta+8)\right] \\
=\left(\frac{1}{6}\right)\left[1-\frac{\theta+4}{\left(\theta^{2}+8 \theta-5\right)^{\frac{1}{2}}}\right]<0 \Leftrightarrow \\
\theta+4>\left(\theta^{2}+8 \theta-5\right)^{\frac{1}{2}} \Leftrightarrow \theta^{2}+8 \theta+16>\theta^{2}+8 \theta-5 \Leftrightarrow 11>-5 . \\
\frac{\partial \frac{1+\theta+\sqrt{\theta^{2}+8 \theta-5}}{6}}{\partial \theta}=\left(\frac{1}{6}\right)\left[1+\frac{1}{2}\left(\theta^{2}+8 \theta-5\right)^{-\frac{1}{2}}(2 \theta+8)\right]>0 .
\end{gathered}
$$

The lower root always lies in $(0,1 / 2)$ as long as

$$
\begin{aligned}
\frac{1+\theta-\sqrt{\theta^{2}+8 \theta-5}}{6} & >0 \Leftrightarrow 1+\theta>\sqrt{\theta^{2}+8 \theta-5} \Leftrightarrow 1+2 \theta+\theta^{2}>\theta^{2}+8 \theta-5 \\
& \Leftrightarrow 6>6 \theta \Leftrightarrow 1>\theta
\end{aligned}
$$

and

$$
\frac{1}{2}>\frac{1+\theta-\sqrt{\theta^{2}+8 \theta-5}}{6} \Leftrightarrow 2>\theta-\sqrt{\theta^{2}+8 \theta-5}
$$


which are indeed true. One immediate implication is that the upper root is positive:

$$
\frac{1+\theta+\sqrt{\theta^{2}+8 \theta-5}}{6}>0 \text {. }
$$

To determine whether the upper root is less than $1 / 2$, consider

$$
\begin{aligned}
\frac{1}{2} & >\frac{1+\theta+\sqrt{\theta^{2}+8 \theta-5}}{6} \Leftrightarrow 3>1+\theta+\sqrt{\theta^{2}+8 \theta-5} \Leftrightarrow 2-\theta>\sqrt{\theta^{2}+8 \theta-5} \\
& \Leftrightarrow 4-4 \theta+\theta^{2}>\theta^{2}+8 \theta-5 \Leftrightarrow 9>12 \theta \Leftrightarrow 3 / 4>\theta .
\end{aligned}
$$

Hence, if $\theta \in\left(\sqrt{21}-4, \frac{3}{4}\right)$ then equilibrium cut-offs are $x \in\left\{0, \frac{1+\theta-\sqrt{\theta^{2}+8 \theta-5}}{6}, \frac{1+\theta+\sqrt{\theta^{2}+8 \theta-5}}{6}\right\}$, where

$$
0<\frac{1+\theta-\sqrt{\theta^{2}+8 \theta-5}}{6}<\frac{1+\theta+\sqrt{\theta^{2}+8 \theta-5}}{6}<\frac{1}{2}
$$

If $\theta \in\left[\frac{3}{4}, 1\right)$ then $x \in\left\{0, \frac{1+\theta-\sqrt{\theta^{2}+8 \theta-5}}{6}, \frac{1}{2}\right\}$.

\section{Appendix B: Example 2}

$$
\begin{aligned}
f^{E}(s)=2 s, F^{E}(s)=s^{2} \\
f^{N E}(s)=2(1-s), F^{N E}(s)=s(2-s) \\
\Gamma(x)=\left(\frac{\gamma f^{E}(x)}{\gamma f^{E}(x)+(1-\gamma) f^{N E}(x)}\right) F^{E}(x)+\left(\frac{(1-\gamma) f^{N E}(x)}{\gamma f^{E}(x)+(1-\gamma) f^{N E}(x)}\right) F^{N E}(x) \\
=\left(\frac{\gamma 2 x}{\gamma 2 x+(1-\gamma) 2(1-x)}\right) x^{2}+\left(\frac{(1-\gamma) 2(1-x)}{\gamma 2 x+(1-\gamma) 2(1-x)}\right) x(2-x) \\
=\left(\frac{\gamma x^{3}}{\gamma x+(1-\gamma)(1-x)}\right)+\left(\frac{(1-\gamma) x(1-x)(2-x)}{\gamma x+(1-\gamma)(1-x)}\right) \\
=\frac{\gamma x^{3}+(1-\gamma) x(1-x)(2-x)}{\gamma x+(1-\gamma)(1-x)} \\
=\frac{\gamma x^{3}+2(1-\gamma) x-3(1-\gamma) x^{2}+(1-\gamma) x^{3}}{\gamma x+(1-\gamma)(1-x)} \\
=\frac{x^{3}-3(1-\gamma) x^{2}+2(1-\gamma) x}{\gamma x+(1-\gamma)(1-x)}
\end{aligned}
$$




$$
\begin{aligned}
\operatorname{Pr}\left(E \mid s_{1}=x, s_{2} \leq x\right) & =\frac{\gamma f^{E}(x) F^{E}(x)}{\gamma f^{E}(x) F^{E}(x)+(1-\gamma) f^{N E}(x) F^{N E}(x)} \\
& =\frac{\gamma 2 x x^{2}}{\gamma 2 x x^{2}+(1-\gamma) 2(1-x) x(2-x)} \\
& =\frac{\gamma x^{3}}{\gamma x^{3}+(1-\gamma)(1-x) x(2-x)} \\
& =\frac{\gamma x^{3}}{\gamma x^{3}+(1-\gamma)\left(2 x-3 x^{2}+x^{3}\right)} \\
& =\frac{\gamma x^{2}}{x^{2}+(1-\gamma)(2-3 x)}
\end{aligned}
$$

If a firm applies when its signal exceeds $x$, the probability of conviction is

$$
\begin{aligned}
& \gamma+(1-\gamma)\left[1-\operatorname{Pr}\left(s_{1}<x \mid N E\right) \operatorname{Pr}\left(s_{2}<x \mid N E\right)\right] \\
= & \gamma+(1-\gamma)\left[1-x^{2}(2-x)^{2}\right] .
\end{aligned}
$$

We will consider the probability of conviction for the Pareto-efficient equilibrium. For this purpose:

$$
\begin{aligned}
\Phi(x)= & \Gamma(x)\left\{\operatorname{Pr}\left(E \mid s_{1}=x, s_{2} \leq x\right)-\theta\right\}+\left(\frac{1-\theta}{2}\right)[1-\Gamma(x)] \\
= & \left(\frac{x^{3}-3(1-\gamma) x^{2}+2(1-\gamma) x}{\gamma x+(1-\gamma)(1-x)}\right)\left(\frac{\gamma x^{2}}{x^{2}+(1-\gamma)(2-3 x)}-\theta\right) \\
& +\left(\frac{1-\theta}{2}\right)\left(1-\frac{x^{3}-3(1-\gamma) x^{2}+2(1-\gamma) x}{\gamma x+(1-\gamma)(1-x)}\right) .
\end{aligned}
$$

Let $x^{*}$ be the maximal equilibrium cut-off. Note that $\Phi(1)=1-\theta>0$. Hence, if $\Phi(x)>0 \forall x \in[0,1]$ then $x^{*}=0$ and otherwise it is the largest real root of $\Phi(x)=0$ within $[0,1]$.

If firms have public signals, leniency is used for the Pareto-efficient equilibrium when

$$
\begin{aligned}
& \operatorname{Pr}\left(E \mid s_{1}, s_{2}\right)>\theta \Leftrightarrow \\
& \frac{\gamma f^{E}(x) F^{E}(x)}{\gamma f^{E}(x) f^{E}(x)+(1-\gamma) f^{N E}(x) f^{N E}(x)}>\theta \Leftrightarrow \\
& \frac{\gamma 2 s_{1} 2 s_{2}}{\gamma 2 s_{1} 2 s_{2}+(1-\gamma) 2\left(1-s_{1}\right) 2\left(1-s_{2}\right)}>\theta \Leftrightarrow \\
& s_{1}>\frac{\theta(1-\gamma)\left(1-s_{2}\right)}{(\gamma-\theta) s_{2}+\theta(1-\gamma)},
\end{aligned}
$$

where $(\gamma-\theta) s_{2}+\theta(1-\gamma)>0$. Hence, the probability of using leniency conditional 
on NE is

$$
\begin{aligned}
& \operatorname{Pr}\left(\operatorname{Pr}\left(E \mid s_{1}, s_{2}\right)>\theta \mid N E\right)=\int_{0}^{1} \int_{\frac{\theta(1-\gamma)\left(1-s_{2}\right)}{(\gamma-\theta) s_{2}+\theta(1-\gamma)}}^{1} f^{N E}\left(s_{1}\right) d s_{1} f^{N E}\left(s_{2}\right) d s_{2} \\
&=\int_{0}^{1} \int_{\frac{\theta(1-\gamma)\left(1-s_{2}\right)}{(\gamma-\theta) s_{2}+\theta(1-\gamma)}}^{1} 2\left(1-s_{1}\right) d s_{1} 2\left(1-s_{2}\right) d s_{2} \\
&\left.=\int_{0}^{1} s_{1}\left(2-s_{1}\right)\right]_{\frac{\theta(1-\gamma)\left(1-s_{2}\right)}{(\gamma-\theta) s_{2}+\theta(1-\gamma)}}^{1} 2\left(1-s_{2}\right) d s_{2} \\
&=\int_{0}^{1}\left[1-\left(\frac{\theta(1-\gamma)\left(1-s_{2}\right)}{(\gamma-\theta) s_{2}+\theta(1-\gamma)}\right)\left(2-\frac{\theta(1-\gamma)\left(1-s_{2}\right)}{(\gamma-\theta) s_{2}+\theta(1-\gamma)}\right)\right] 2\left(1-s_{2}\right) d s_{2} .
\end{aligned}
$$

The probability of conviction is then

$\gamma+(1-\gamma) \int_{0}^{1}\left[1-\left(\frac{\theta(1-\gamma)(1-s)}{(\gamma-\theta) s+\theta(1-\gamma)}\right)\left(2-\frac{\theta(1-\gamma)(1-s)}{(\gamma-\theta) s+\theta(1-\gamma)}\right)\right] 2(1-s) d s$

\section{Appendix C}

In evaluating when $\Gamma(x)=\operatorname{Pr}\left(s_{2} \leq x \mid s_{1}=x\right)$ is non-decreasing in $x$, there are two countervailing forces. To express them, consider $\Gamma(x)=\operatorname{Pr}\left(s_{2} \leq y \mid s_{1}=z\right)$. As $y$ increases, $\operatorname{Pr}\left(s_{2} \leq y \mid s_{1}=z\right)$ is non-decreasing for the obvious reason that a cdf is non-decreasing. But, by A1, a rise in firm 1's signal causes a FOSD shift in the cdf on firm 2's signal which means $\operatorname{Pr}\left(s_{2} \leq y \mid s_{1}=z\right)$ is non-increasing in $z$. To better understand when $\Gamma(x)$ is non-decreasing in $x$, consider the formulation in Section 6 when firms' signals are conditionally independent:

$$
\Gamma(x)=\operatorname{Pr}\left(s_{2} \leq x \mid s_{1}=x\right)=\operatorname{Pr}\left(s_{2} \leq x, E \mid s_{1}=x\right)+\operatorname{Pr}\left(s_{2} \leq x, N E \mid s_{1}=x\right)
$$

It follows from conditional independence that

$$
\begin{aligned}
\operatorname{Pr}\left(s_{2} \leq x, E \mid s_{1}=x\right) & =\frac{\operatorname{Pr}\left(s_{2} \leq x, E, s_{1}=x\right)}{\operatorname{Pr}\left(s_{1}=x\right)}=\frac{\operatorname{Pr}\left(s_{2} \leq x, s_{1}=x \mid E\right) \operatorname{Pr}(E)}{\operatorname{Pr}\left(s_{1}=x\right)} \\
& =\frac{\operatorname{Pr}\left(s_{2} \leq x \mid E\right) \operatorname{Pr}\left(s_{1}=x \mid E\right) \operatorname{Pr}(E)}{\operatorname{Pr}\left(s_{1}=x\right)} \\
& =\frac{\operatorname{Pr}\left(s_{2} \leq x \mid E\right)\left[\operatorname{Pr}\left(s_{1}=x, E\right) / \operatorname{Pr}(E)\right] \operatorname{Pr}(E)}{\operatorname{Pr}\left(s_{1}=x\right)} \\
& =\operatorname{Pr}\left(E \mid s_{1}=x\right) \operatorname{Pr}\left(s_{2} \leq x \mid E\right)
\end{aligned}
$$

and

$$
\operatorname{Pr}\left(s_{2} \leq x, N E \mid s_{1}=x\right)=\operatorname{Pr}\left(N E \mid s_{1}=x\right) \operatorname{Pr}\left(s_{2} \leq x \mid N E\right)
$$


Inserting in the above,

$$
\begin{aligned}
\Gamma(x) & =\operatorname{Pr}\left(s_{2} \leq x \mid s_{1}=x\right) \\
& =\operatorname{Pr}\left(E \mid s_{1}=x\right) \operatorname{Pr}\left(s_{2} \leq x \mid E\right)+\operatorname{Pr}\left(N E \mid s_{1}=x\right) \operatorname{Pr}\left(s_{2} \leq x \mid N E\right) \\
& =\left(\frac{\gamma f^{E}(x)}{\gamma f^{E}(x)+(1-\gamma) f^{N E}(x)}\right) F^{E}(x)+\left(\frac{(1-\gamma) f^{N E}(x)}{\gamma f^{E}(x)+(1-\gamma) f^{N E}(x)}\right) F^{N E}(x) \\
& =\left(\frac{\gamma\left[f^{E}(x) / f^{N E}(x)\right]}{\gamma\left[f^{E}(x) / f^{N E}(x)\right]+(1-\gamma)}\right) F^{E}(x)+\left(\frac{1-\gamma}{\gamma\left[f^{E}(x) / f^{N E}(x)\right]+(1-\gamma)}\right) F^{N E}(x) \\
& =\left(\frac{\gamma \mu(x)}{\gamma \mu(x)+(1-\gamma)}\right) F^{E}(x)+\left(\frac{1-\gamma}{\gamma \mu(x)+(1-\gamma)}\right) F^{N E}(x) \\
& =F^{N E}(x)-\left(\frac{\gamma f^{E}(x)}{\gamma f^{E}(x)+(1-\gamma) f^{N E}(x)}\right)\left[F^{N E}(x)-F^{E}(x)\right]
\end{aligned}
$$

where

$$
\mu(x) \equiv \frac{f^{E}(x)}{f^{N E}(x)}
$$

The MLRP is that $\mu^{\prime}(x)>0$.

$$
\begin{aligned}
\Gamma^{\prime}(x)= & \left(\frac{\gamma \mu^{\prime}(x)[\gamma \mu(x)+(1-\gamma)]-\gamma^{2} \mu(x) \mu^{\prime}(x)}{[\gamma \mu(x)+(1-\gamma)]^{2}}\right) F^{E}(x)+\left(\frac{\gamma \mu(x)}{\gamma \mu(x)+(1-\gamma)}\right) f^{E}(x) \\
& -\left(\frac{(1-\gamma) \gamma \mu^{\prime}(x)}{[\gamma \mu(x)+(1-\gamma)]^{2}}\right) F^{N E}(x)+\left(\frac{1-\gamma}{\gamma \mu(x)+(1-\gamma)}\right) f^{N E}(x) \\
\Gamma^{\prime}(x)= & \left(\frac{\gamma(1-\gamma) \mu^{\prime}(x)}{[\gamma \mu(x)+(1-\gamma)]^{2}}\right) F^{E}(x)+\left(\frac{\gamma \mu(x)}{\gamma \mu(x)+(1-\gamma)}\right) f^{E}(x) \\
\Gamma^{\prime}(x)= & \left(\frac{\gamma \mu(x) f^{E}(x)+(1-\gamma) f^{N E}(x)}{\gamma \mu(x)+(1-\gamma)}\right)-\left(\frac{\gamma(1-\gamma) \mu^{\prime}(x)}{[\gamma \mu(x)+(1-\gamma)]^{2}}\right)\left[F^{N E}(x)-F^{E}(x)\right] \\
= & \left(\frac{1-\gamma) f^{N E}(x)+\left(\frac{1-\gamma)+(1-\gamma)}{\gamma \mu}\right) f^{N E}(x)}{\gamma \mu(x)+(1-\gamma)}\right) \times \\
& {\left[\gamma \mu(x) f^{E}(x)+(1-\gamma) f^{N E}(x)-\left(\frac{\gamma(1-\gamma) \mu^{\prime}(x)}{\gamma \mu(x)+(1-\gamma)}\right)\left[F^{N E}(x)-F^{E}(x)\right]\right] . }
\end{aligned}
$$

Thus, $\Gamma^{\prime}(x)>0$ iff

$$
\frac{\gamma \mu(x) f^{E}(x)+(1-\gamma) f^{N E}(x)}{\gamma \mu(x)+(1-\gamma)}>\left(\frac{\gamma(1-\gamma) \mu^{\prime}(x)}{[\gamma \mu(x)+(1-\gamma)]^{2}}\right)\left[F^{N E}(x)-F^{E}(x)\right] .
$$

The LHS is positive. The RHS is also positive because $F^{N E}(x)-F^{E}(x)>0$ by FOSD and $\mu^{\prime}(x)>0$ by the MLRP. If $F^{N E}(x)$ and $F^{E}(x)$ are not too different - 
which means the signal is not too informative - then this condition holds. If $\gamma$ is sufficiently close to 0 or to 1 - so there is not too much uncertainty about the CA's ability to successfully prosecute - then again this condition holds. Neither case is particularly helpful as $0<<\gamma<<1$ is most natural and we'd like the signal to be fairly informative, otherwise private information is not much of an issue.

We can show that $\Gamma^{\prime}(x)>0$ for Example 2:

$$
f^{E}(x)=2 x, f^{N E}(x)=2(1-x) .
$$

Since

$$
\Gamma(x)=\frac{x^{3}-3(1-\gamma) x^{2}+2(1-\gamma) x}{\gamma x+(1-\gamma)(1-x)}
$$

then

$$
\begin{aligned}
\operatorname{sign}\left\{\Gamma^{\prime}(x)\right\}= & \operatorname{sign}\left\{\left[3 x^{2}-6(1-\gamma) x+2(1-\gamma)\right][\gamma x+(1-\gamma)(1-x)]\right. \\
& \left.-\left[x^{3}-3(1-\gamma) x^{2}+2(1-\gamma) x\right](2 \gamma-1)\right\} \\
= & \operatorname{sign}\left\{x^{3}(2 \gamma-1)+(1-\gamma)^{2}[1-3 x(1-x)]\right\}
\end{aligned}
$$

Note that $1-3 x(1-x)>0, \forall x$ since $x(1-x)$ is maximized at $x=1 / 2$ and thus $1-3 x(1-x)>.25$.

$$
\begin{aligned}
\frac{\partial\left[x^{3}(2 \gamma-1)+(1-\gamma)^{2}[1-3 x(1-x)]\right]}{\partial \gamma} & =2 x^{3}-2(1-\gamma)[1-3 x(1-x)] \\
& \gtreqless 0 \text { as } 1-\gamma \lesseqgtr \frac{x^{3}}{1-3 x(1-x)} \\
& \gtreqless 0 \text { as } \gamma \gtreqless 1-\frac{x^{3}}{1-3 x(1-x)} \\
\frac{\partial^{2}\left[x^{3}(2 \gamma-1)+(1-\gamma)^{2}[1-3 x(1-x)]\right]}{\partial \gamma^{2}}=2[1-3 x(1-x)]>0 . &
\end{aligned}
$$

If $1-\frac{x^{3}}{1-3 x(1-x)} \leq 0$ then $x^{3}(2 \gamma-1)+(1-\gamma)^{2}[1-3 x(1-x)]$ is increasing in $\gamma$ in which case a sufficient condition for it to be positive everywhere is that it be positive at $\gamma=0$ :

$$
-x^{3}+3 x^{2}-3 x+1>0 .
$$

Note that

$$
\frac{\partial\left[-x^{3}+3 x^{2}-3 x+1\right]}{\partial x}=-3 x^{2}+6 x-3=-3(1-x)^{2}<0
$$

and, when evaluated at $x=1$,

$$
-x^{3}+3 x^{2}-3 x+1=0,
$$

Hence, $-x^{3}+3 x^{2}-3 x+1>0 \forall x<1$. Therefore, if $1-\frac{x^{3}}{1-3 x(1-x)} \leq 0$ then

$$
x^{3}(2 \gamma-1)+(1-\gamma)^{2}[1-3 x(1-x)]>0
$$


and $\Gamma^{\prime}(x)>0$. Now suppose $1-\frac{x^{3}}{1-3 x(1-x)}>0$. In that case, $x^{3}(2 \gamma-1)+(1-\gamma)^{2}[1-3 x(1-x)]$ is minimized at $\gamma=1-\frac{x^{3}}{1-3 x(1-x)}$ (given it is convex). Thus, we want to evaluate $x^{3}(2 \gamma-1)+(1-\gamma)^{2}[1-3 x(1-x)]$ at $\gamma=1-\frac{x^{3}}{1-3 x(1-x)}$ :

$$
\begin{aligned}
& x^{3}\left(2-\frac{2 x^{3}}{1-3 x(1-x)}-1\right)+\left(\frac{x^{3}}{1-3 x(1-x)}\right)^{2}[1-3 x(1-x)] \\
= & x^{3}\left(\frac{1-3 x(1-x)-2 x^{3}}{1-3 x(1-x)}\right)+\frac{x^{6}}{1-3 x(1-x)},
\end{aligned}
$$

which is positive iff

$$
\begin{aligned}
x^{3}\left(1-3 x(1-x)-2 x^{3}\right)+x^{6} & >0 \Leftrightarrow 1-3 x(1-x)-x^{3}>0 \Leftrightarrow \\
1-3 x(1-x) & >x^{3} \Leftrightarrow 1>\frac{x^{3}}{1-3 x(1-x)} \Leftrightarrow 1-\frac{x^{3}}{1-3 x(1-x)}>0
\end{aligned}
$$

which is assumed. This concludes the proof that if

$$
f^{E}(x)=2 x, f^{N E}(x)=2(1-x)
$$

then $\Gamma^{\prime}(x)>0, \forall x$. 


\section{References}

[1] Bigoni, Maria, Sven-Olof Fridolfsson, Chloé Le Coq, and Giancarlo Spagnolo, "Trust, Salience, and Deterrence: Evidence from an Antitrust Experiment," SSE/EFI Working Paper Series in Economics and Finance No. 696, January 2010.

[2] Harrington, Joseph E., Jr., "Optimal Corporate Leniency Programs," Journal of Industrial Economics, 56 (2008), 215-246.

[3] Harrington, Joseph E., Jr. and Myong-Hun Chang, "Modelling the Birth and Death of Cartels with an Application to Evaluating Antitrust Policy," Journal of the European Economic Association, 7 (2009), 1400-1435.

[4] Motta, Massimo and Michele Polo, "Leniency Programs and Cartel Prosecution," International Journal of Industrial Organization, 21 (2003), 347-379.

[5] Pinna, Andrea, "Optimal Leniency Programs in Antitrust," Università di Cagliari \& Università di Sassari, CRENoS Working Paper 2010/18.

[6] Sauvagnat, Julien, "Prosecution and Leniency Programs: A Fool's Game," Toulouse School of Economics Working Paper Series 10-188, September 2010.

[7] Silbye, Frederik, "Optimal Leniency Programs with Case-Dependent Fine Discounts," in Topics in Competition Policy: Cartels, Leniency, and Price Discrimination, PhD Thesis, University of Copenhagen, August 2010a.

[8] Silbye, Frederik, "Asymmetric Evidence and Optimal Leniency Programs," in Topics in Competition Policy: Cartels, Leniency, and Price Discrimination, $\mathrm{PhD}$ Thesis, University of Copenhagen, August 2010b.

[9] Spagnolo, Giancarlo, "Leniency and Whistleblowers in Antitrust," in Handbook of Antitrust Economics, Paolo Buccirossi, ed., Cambridge, Mass.: The MIT Press, 2008. 
Figure $6 \quad$ Prob(Public) for $\theta=0.1, \ldots, 0.9$

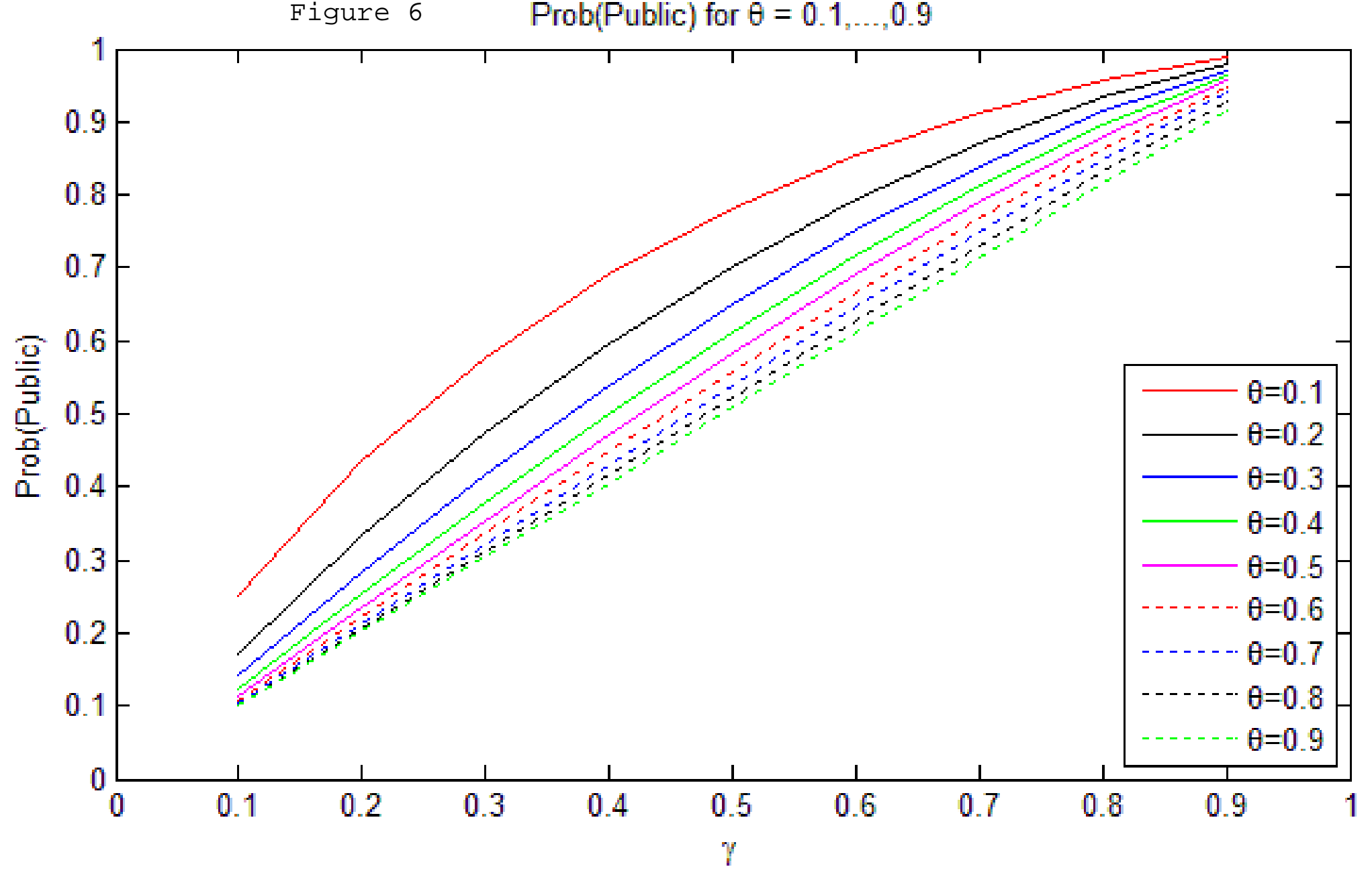




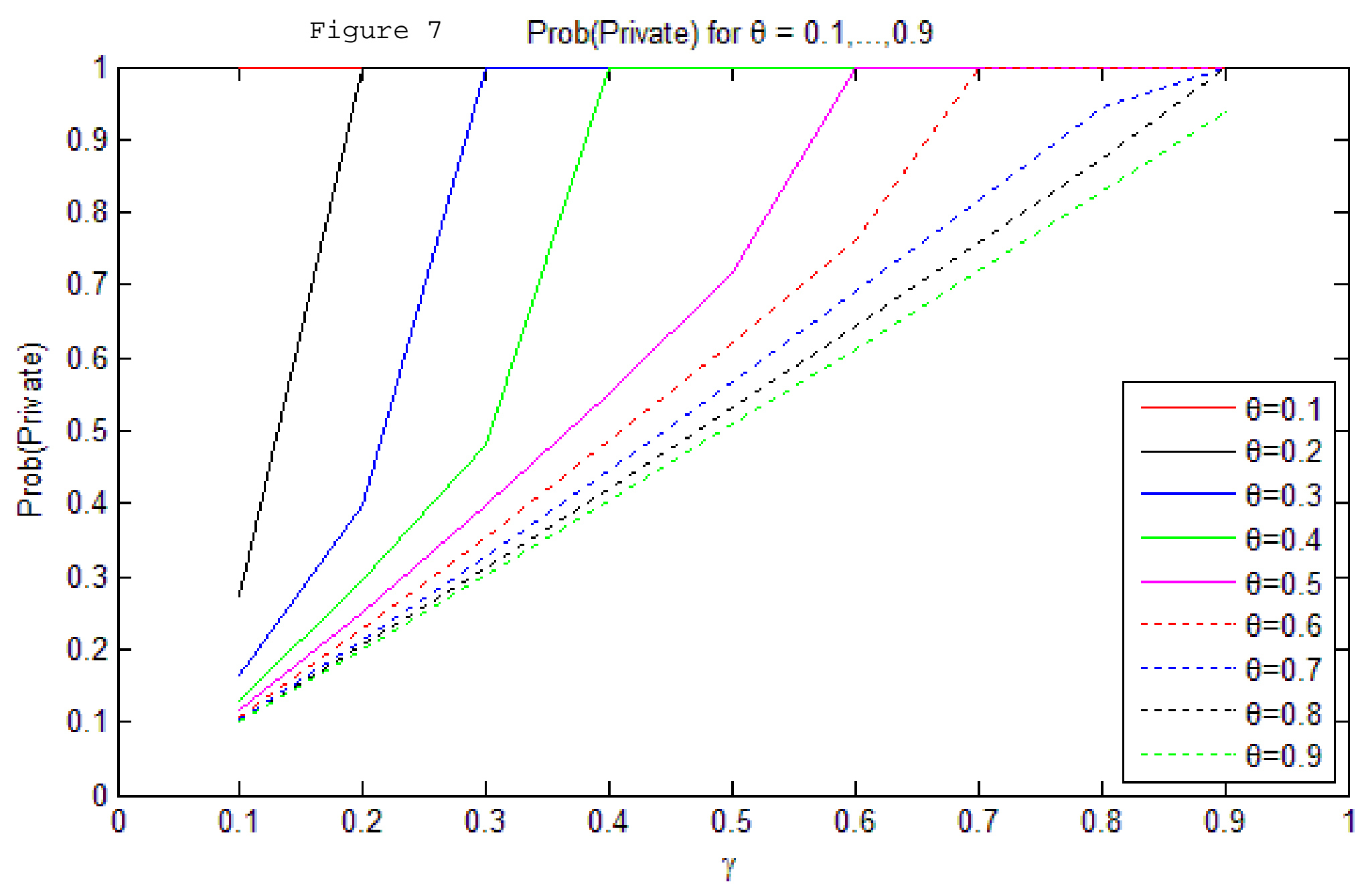

